\title{
Law Teaching for the Conceptual Age
}

\author{
Paula A. Franzese
}

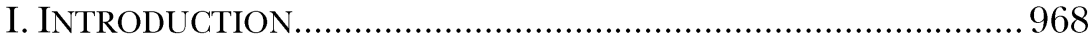

II. WHOLE MIND TEACHING AND LEARNING ............................. 974

A. Staying Relevant in the Conceptual Age ..................974

B. Conceptual Teaching: The Big Picture .................... 982

C. Harnessing the Power of Mirror Neurons................ 989

III. TOOLS FOR WHOLE MIND TEACHING AND LEARNING........... 995

A. Empathy as Pathway to Learning.............................. 995

B. The Power of Story .................................................. 998

C. Using Play to Enhance Whole-Mind Teaching and

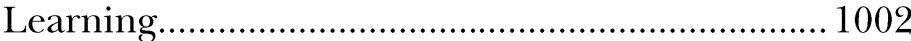

D. Using Symphony to Appreciate Interconnectivity. 1005

E. Meaning as Pathway to Purpose.............................. 1007

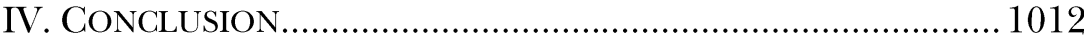

\footnotetext{
* Peter W. Rodino Professor of Law, Seton Hall University School of Law. I thank my colleagues at Seton Hall Law School, exceptional teachers all, for their generosity in sharing their pedagogical experiences, and my students, present, past, and future. They are even better than they know, and I am better because of them. This article benefited immeasurably because of the superb research assistance of Josh Fischer and Jacqulyn Simmons. Thank you to Danielle Steele and Kevin Small, who while upperclass students at Seton Hall Law School graciously agreed time and again to convincingly role-play for my classes. Those simulations became the basis for the "Danielle and Kevin" series, described herein.
} 
The truth is, a great mind must be androgynous. -Samuel Taylor Coleridge

\section{INTRODUCTION}

We are teaching law in challenging times. In response to the economic downturn, ${ }^{1}$ diminished employment prospects for law school graduates, ${ }^{2}$ the ever-escalating costs of a legal education, ${ }^{3}$

1 See generally RichaRd Susskind, The END OF LAWYERS? RETHINKING THE NATURE OF LEGAL SERVICES (2008) (citing the economic shifts that have yielded a "new normal" for the provision of legal services); Thomas D. MORgan, THE VANishing American LAWYER (2010) (studying changes in legal profession in response to pre- and postrecession shifts); Vincent Rougeau, Four Ways to Fix Law School, U.S. NEwS \& WORLD REPORT, (Feb. 5, 2013, 2:45 PM), http://www.usnews.com/opinion/articles $/ 2013 / 02 / 05 /$ four-ways-to-fix-law-school (in the presence of "extraordinary worldwide economic uncertainty, one begins to wonder what type of future exists for new lawyers.").

2 Brian Z. TAMANAHA, FAILING LAW SchOOLS ix (2012) ("Many law graduates cannot find jobs as lawyers, enduring the worst market for legal employment in decades."); Ethan Bronner, Law Schools' Applications Fall as Costs Rise and Jobs Are Cut, N.Y. TimeS, Jan. 30, 2013, at A1; David Segal, Is Law School a Losing Game?, N.Y. TimeS, Jan. 8, 2011, at BU1; David Segal, Law Students Lose the Grant Game as Schools Win, N.Y. Times, Apr. 30, 2011, at BU1; Joe Palazzalo, A Dozen Law Schools Hit With Lawsuits Over Job Data, WALl ST. J. L. Blog (Feb. 2, 2012, 2:28 PM), http://blogs.wsj.com/law/2012/ 02/01/a-dozen-law-schools-hit-with-lawsuits-over-jobs-data/; Sarah Mui, Grads Sue New York Law School and Cooley Law, Saying They Inflated Job and Salary Stats, A.B.A. J. (Aug. 10, 2011, 5:36 PM), http://www.abajournal.com/news/article/grads_sue_new_york_ law_school_and_cooley_law_saying_they_inflated_job_and_s/.

3 Data collected from law schools by U.S. News \& World Report reveals that " $85 \%$ of law graduates from ABA-accredited schools boasted an average debt load of $\$ 98,500$." Student debt-service exceeded $\$ 120,000$ at 29 law schools. William D. Henderson \& Rachel M. Zahorsky, The Law School Bubble: How Long Will It Last if Law Grads Can't Pay Bills, A.B.A. J. (Jan. 1, 2012), http://www.abajournal.com/magazine/ article/the_law_school_bubble_how_long_will_it_last_if_law_grads_cant_pay_bills/. In contrast, nine months after commencement "only $68 \%$ of those grads reported employment in positions that require a J.D. Less than $51 \%$ found employment in private law firms." Id:; see also Elizabeth G. Olson, Does Law School Have a Future? CNN MONEY (Dec. 18, 2012), http://management. fortune.cnn.com/2012/12/18/doeslaw-school-have-a-future/ (noting that, to date, more than half of the country's 200 law schools "are cutting back the size of their entering classes, and many are handing out more student financial aid, which effectively lowers tuition. But the powerful economic reality is that law schools are big business, with tuition high enough that students graduate with an average of more than $\$ 100,000$ each in debt."); TAMANAHA, supra note 2, at 181 ("The economic model of law schools is unsustainable."); see generally Law Professors Question Sustainability of Legal Education, Urge Changes, INSIDE HiGHER ED (Mar. 8, 2013), http://www.insidehighered.com/quicktakes/2013/ 03/08/law-professors-question-sustainability-legal-education-urge-changes (urging the ABA to "alter the economics" of law schools, because "legal education cannot continue on the current trajectory."); Deborah J. Merritt, Letter to the ABA, Mar. 10, 
declining law student enrollments, ${ }^{4}$ fickle and changing client demands, ${ }^{5}$ and an increasingly global playing field, ${ }^{6}$ both the academy and the practice of law continue to undergo rather seismic shifts. ${ }^{7}$ Moreover, the smaller numbers of students who are choosing law school are primarily members of the Millennial "Generation C" - a group with learning preferences, strengths and weaknesses unlike those of most of their professors.

Against the backdrop of an irrevocably changed legal landscape and law school constituency, a host of proposals have emerged for reform of the academy's educational model. The recession has rendered inescapable a collective reckoning with the long-held criticism that "law schools teach students how to think like a lawyer, but not how to be one." Most of the discussion for law school

2013, http://www.lawschoolcafe.org/thread/letter-to-the-aba/ ("[T]uition has climbed dramatically, scholarships rarely address need, entry-level jobs have contracted, and salaries in those jobs have declined."); Jennifer Smith, Academy's Heavyweights Opine on Law Schools'Problems, WALL ST. J. L. BLOG (Mar. 7, 2013, 6:48 PM), http://blogs.wsj.com/law/2013/03/07/academys-heavyweights-opine-on-law-schoolproble ms/ (citing a letter from academy members to the newly-minted ABA Task Force on Legal Education); Paul L. Caron, The Law School Crisis: What Would fimmy McMillan Do?, July 1, 2012, available at http://ssrn.com/abstract=2231110 (explaining that the current model is "simply unsustainable").

4 Olson, supra note 3 ("Law school enrollment is down by about $15 \%$ from 2010 ," and the number of students "taking the law school admissions test in October 2012 was down by $16.4 \%$ from the previous year, hitting its lowest level since 1999.").

5 A Less Gilded Future, ECONOMIST, May 5, 2011, available at http:/ / www.economist. com/node/18651114; Larry Ribstein, The Death of Big Law, 210 WIS. L. REV. 749 (2010); Elie Mystal, Will American Law Schools Adapt to the Changing Legal Market? Ever? Do They Even Care?, ABOvE THE LAW (July 16, 2012, 2:14 PM), http://abovethelaw.com/ 2012/07/will-american-law-schools-adapt-to-the-changing-legal-market-ever-do-theyeven-care/.

${ }^{6}$ Rougeau, supra note 1 at 1 (noting "the realities of an integrated global economic environment").

7 Id. ("The American legal profession is facing challenges unlike any we have witnessed before. The average debt load of law school students continues to increase, major law firms have slashed the number of entry-level associates they hire, and observers do not expect a return to the days when graduates could expect to earn sixfigure salaries despite little training in the day-to-day practice of law."); see also Olson, supra note 3 (noting pending lawsuits brought by disgruntled graduates against their law school alma maters and stating, "Like it or not, law schools may have to up their game if they are going to overcome the objections of their own disgruntled graduates.").

8 See infra note 66 and accompanying text.

9 Jordan Weissman, Why Law Schools Are So Bad at Creating Lawyers (and How to Fix It), The ATLANTiC (Nov. 22, 2011, 9:30 AM), http://www.theatlantic.com/business/ archive/2011/11/why-law-schools-are-so-bad-at-creating-lawyers-and-how-to-fixit/248889/. In 2007, the Clinical Legal Education Association issued the criticism that "law schools are not fully committed to preparing students for practice." ROY STUCKEY, BEST PRACTICES FOR LEGAL EDUCATION 16 (2007). 
reinvention has focused on enhancing skills-based practical learning opportunities so that graduates will be better prepared for the practice of law. ${ }^{10}$ Those proposals have placed considerable emphasis on the second and third years of law school, with some advocating for in-thefield training, ${ }^{11}$ others embracing an exclusively clinical model ${ }^{12}$ and still others advancing the position that the third year of law school be dispensed with all together to decrease student debt-service and hasten on-site practical learning. ${ }^{13}$ Recently, discussion has turned to the propriety of requiring law students to submit to a post-graduation apprenticeship akin to the prototype in place for medical residents. ${ }^{14}$

Not enough attention has been paid, however, to how law schools can enhance the caliber, relevance, and appeal of the law school curricula in general and the first-year core and required course load in particular. ${ }^{15}$ The core classes and required courses that we teach can do more to equip our students to maneuver effectively in these dramatically reshaped times. Our students' success and relevance (and, indeed, our own) will depend on their (and our) capacity to hone in all courses both the traditionally taught "textual" skills as well as the increasingly important "conceptual" skills that the legal academy too often overlooks. The former are the hallmarks of conventional law school pedagogy, which prizes the linear, logical and analytical. ${ }^{16}$

10 Olson, supra note 3. See generally Kyle McEntee, Patrick J. Lynch, \& Derek M. Tokaz, The Crisis in Legal Education: Dabbling in Disaster Planning, 46 U. MicH. J.L. REFORM 225, 258 (advancing skills-based models that could include modular teaching, using part-time faculty for finite modules and trade-like "lawyer academies").

11 Bronner, supra note 2. For example, Northeastern Law School and Washington and Lee Law School remodeled the third year curriculum, allowing students to serve at law clinics or internships in the field. Stanford Law School expanded its third year curriculum to facilitate opportunities for its students to earn joint degrees. Olson, supra note 3 .

12 Olson, supra note 3; see also Bronner, supra note 2.

13 Daniel B. Rodriguez \& Samuel Estreicher, Make Law Schools Earn a Third Year, N.Y. TimeS, Jan. 17, 2013, at A27.

14 John J. Farmer, Jr., To Practice Law, Apprentice First, N.Y. Times, Feb. 17, 2013, at A17; see also Ethan Bronner, To Place Graduates, Law Schools Are Opening Firms, N.Y. Times, Mar. 8, 2013, at A14 (describing move to create equivalent of teaching hospital for law school graduates).

${ }_{15}$ Andrew Cohen, How Not to Fix Law School, CBSNEwS.COM (Nov. 10, 2006, 9:28 AM), http:/ / www.cbsnews.com/2100-18567_162-2170558.html. In 2009, Harvard Law School announced that its first year curriculum would henceforth include more statutory interpretation, problem solving, and international law. The first core curricular overhaul in approximately 130 years, the changes were met with the criticism that "America's most famous law school" has decided to offer "variations of the same tired curriculum that has caused generation after generation of lawyers to emerge from law school unprepared for the real world of law." Id.

${ }_{16}$ See generally Ruta K. Stropus, Mend It, Bend It, and Extend It: The Fate of Traditional Law School Methodology in the 21 $1^{\text {st }}$ Century, 27 LoY. U. CHI. L.J. 449 (1996) (citing 
Those attributes are referred to metaphorically as the products of the brain's "left hemisphere" functions, which are most certainly essential to critical deductive reasoning. ${ }^{17}$ In fact, much of what we tend to do in the law school classroom is aimed at honing left-brain thinking. Right-brain thinking, by contrast, is more contextual. ${ }^{18}$ Sometimes referred to as "high concept" or "high touch," ${ }^{19}$ it includes the abilities to glean patterns, perceive connections, craft meaningful narratives, navigate ethical quandaries, and "understand the subtleties of human interaction." ${ }^{\prime 0}$

It behooves us to give those metaphorically "right hemisphere" abilities- the more conceptual and contextual cognitive processes and skill sets-their due in the law school classroom. Indeed, it has been posited that we in the midst of a paradigmatic shift away from the more linear "information age" (where left-brain skills predominated) to the more innovative "conceptual age" where "the future belongs to [those with a right-side mindset]—creators and empathizers, pattern recognizers, and meaning makers." ${ }^{21}$ Today, the left-brain functions are the ones most apt to get outsourced and automated. Understanding more about the sometimes subtle but increasingly more dramatic shift from the linear to the conceptual may help to put into perspective some of the rancor directed at law schools and the perception that we are failing to respond adequately to the marketplace's new economies of supply and demand. ${ }^{22}$ Moreover,

deficiencies of Langdellian approach to law teaching).

17 See M. LezaK, D. Howieson, \& D. Loring, Neuropsychological Assessment (4th ed. 2004); E. GOldBERG, The ExeCutive BRAIN: Frontal LOBES AND THE CIVILIZED MIND (2001); D. Langdon \& E. Warrington, The Role of the Left Hemisphere in Verbal and Spatial Reasoning Tasks, 36 CORTEX 691 (2000); JAAK PANKSEPP, AFFECTIVE Neuroscience: The Foundations Of Human And Animal Emotions (1998); R.D. Abrams \& M. Victor, Principles Of Neurology (4th ed. 1989).

18 See generally Right HemisPhere LANGUAGe Comprehension: Perspectives from Cognitive Neuroscience (M. Beeman \& C. Chiarello eds., 2000); Daniel N. Allen, Gregory P. Strauss, \& Karen A. Kemtes, Hemispheric Contributions to Nonverbal Abstract Reasoning and Problem Solving, 21 Neuropsychology 713 (2007); M.E. Raichle \& J.A. Fiez, Practice Related Changes in Human Functional Anatomy During Non-Motor Learning, 4 Cerebral Cortex 8 (1994).

19 Daniel Pink, A Whole New Mind: Why Right-Brainers Will Rule The Future 48 (2005).

${ }^{20}$ Id. at 52. See generally Lawrence M. Parsons \& Daniel Osherson, New Evidence for Distinct Right and Left Brain Systems for Deductive versus Probabilistic Reasoning, 11 Cerebral Cortex 954 (2001); G. Ratcliff, Spatial Thought, Mental Rotation and the Right Cerebral Hemisphere, 17 Neuropsychology 49 (1979).

21 PINK, supra note 19, at 1.

22 TAMANAHA, supra note 2 ("The economic model of law schools is broken. The cost of a legal education today is substantially out of proportion to the economic opportunities obtained by the majority of graduates."). 
972

rethinking what we do and how we do it through the lens of whole mind integration and its market-based manifestations may well help to save the legal academy from eventual obsolescence.

Significantly, the demographic of which the preponderance of our present and future students are a part, the so-called Millennial "Generation C," is in many ways a product of and driving engine for these conceptual times. The designation "Millennials" refers to the demographic born between 1982 and 2001 that, according to generational trends, are apt to be empathic, cooperative and fiercely interested in deriving meaning from context. ${ }^{23}$ "Generation C" refers to the subset within that demographic of those born between 1982 and 1996. The "C" stands for "connected" content creators, a reference to the digital connectivity that enables members of this group to view and treat content as a collaborative, multisensory and participatory endeavor. Like the generation that succeeds them (those born after 2001, known as "Generation Z" or "Digital Natives"), members of Generation $\mathrm{C}$ like to connect, create, produce and participate.

Able to process multiple contexts simultaneously, our students tend to move rather seamlessly from real to imaginary contexts, allowing for a fluidity and malleability of idea-sharing across multiple platforms. $^{25}$ The demographic of which they are a part relies on frequent feedback, having been raised with lots of instantaneouslygenerated input ${ }^{26}$ as well as the recurrent assurances of parents, teachers and coaches. Their digital and consumer preferences reveal that this group tends to be socially conscious, and seeks out ways to be a part of larger world issues and to leave their imprint. They are digital story-tellers, constantly capturing and sharing their lives and anxious to learn of the stories of others. In fact, they are precisely the sort of audience most apt to appreciate, internalize, practice and apply the teaching and learning tools in the conceptual thinking toolbox.

23 See generally William Strauss \& NeIl Howe, Generations: The History of AMERICA's FUTURE, 1584 TO 2069 (1991).

24 See infra note 69 and accompanying text.

25 Id.

26 In Think Tank: Fix the Workplace, Not the Workers, THE TELEGRAPH (Nov. 6, 2010), http://www.telegraph.co.uk/finance/jobs/8113600/Think-Tank-Fix-the-workplacenot-the-workers.html, Daniel Pink writes:

Consider a typical 28 year-old. From the moment she was born, her world has been rich in feedback. When she presses a button, something happens. When she plays a videogame, she gets a score. When she sends a text message, she hears a sound that confirms it went out. She's lived her whole life on a landscape lush with feedback. Yet, when she steps through the office door, she finds herself in a veritable feedback desert. 
Conceptual thinking is "out of the box," creative and integrative. It asks our students to "think away from the page" to see, and then derive meaning from, the larger contexts of which the cases are a part. Conceptual learning relies on big picture synergies and interconnectivities. It is the circle (and circle within circles) rather than the straight line (and parallel lines). It depends on the more intuitive, empathic, emotionally alert and nonlinear sensibilities.

Conceptual teaching equips our classes with a basis on which to discern not simply what happened in a given case or simulation, but what it means and how that meaning affects and derives content from other contexts, including those that transcend the purely legal. That capability, exercised repeatedly, can help our students to better predict and respond to the changing demands of the clients and constituencies that they will serve. The bulk of those constituents will not depend on counsel to be information-providers or wielders of the status quo. Instead, our graduates will need to be creative problemsolvers, called upon to weed out the underlying causes of various dilemmas and then negotiate solutions and exercise aptitudes that are apt to go beyond the solely legal. ${ }^{27}$ Conceptual thinking can prepare our students to do that. With its emphasis on context, interconnections and the nuances of interpersonal exchange, it can help the students we teach not only to craft a good opinion letter but also to better decode the cues essential to success within the structure of a larger organization, whether a law firm, a corporation or government office. It can hone a skill set that equips them to effectively prepare and also successfully handle a witness or client. With its focus on meta-conceptualizations, it can help to yield the sort of "non-routine savants" ${ }^{28}$ equipped to fashion new and more expansive ways to make their marks with the learning achieved.

Affording our classes the opportunity to develop their metacognitions, or big picture integrative faculties, allows for the sort of expansiveness of perspective that is essential to thrive in integrative legal, business, and economic environments. ${ }^{29}$ Moreover, with enhanced employment opportunities abroad and the increasingly international implications even of domestic legal practice, we add

27 For example, corporations here and abroad now hire lawyers to fill executive posts in human resources, compliance, operations and procurement. The lawyers who fill those posts must apply a repertoire of skills that includes but also transcends the purely legal. That skills set includes counseling, drafting, strategizing, predicting big picture outcomes, mediating office relationships, and making ethical judgment calls.

28 See infra note 58 and accompanying text.

29 Rougeau, supra note 1 (" $[\mathrm{N}]$ ow is the time to position American law schools as world leaders in legal education."). 
value to our students' educational experience by preparing them for transnational work. Further, whole mind teaching can help to put American law schools at the international forefront in legal education. With more students from around the world looking to the United States for advanced degrees and specialty credentials, we are presented with an important opportunity to appeal to a vast cadre of students and practitioners whose education and range of practice is not confined to one national legal system. ${ }^{30}$

This paper explores the dimensions and implications of conceptual thinking for law school teaching. It suggests ways to teach to the whole mind, ${ }^{31}$ thereby helping our students to develop their own whole mind aptitudes by enhancing access to both left and right-brain pathways. Whole-mind teaching can fortify our students' abilities to recognize patterns, forecast outcomes, develop innovative strategies, find the essential interconnectedness among seemingly separate and distinct subject matter, transcend traditional boundaries and appreciate not just "the big picture," but their place in it. Perhaps most essentially, when right-brain empathic pathways are forged, we equip our students with a framework for finding meaning in the work that they will do. That sense of meaning or purpose has its roots in seeds of empathy for the people and the struggles that become the story and the soul of the law.

\section{WHOLE MIND TEACHING AND LEARNING}

\section{A. Staying Relevant in the Conceptual Age}

"The conceptual age"32 is described as the product of a shift in the predicates for achievement and success from skills rooted in the leftbrain linear and analytical (think stock analyst) to those anchored in the more right-brain integrative, empathic, nonlinear and intuitive

30 See id.

31 Here, I draw on my experiences teaching law for close to thirty years. Throughout, I have benefited immeasurably from the lessons learned from my students and colleagues. If it is true that the sort of proficiency able to yield breakthroughs requires at least 10,000 hours spent engaged in the task at hand, I hope here to share meaningfully some of the revelations of my tens of thousands of hours spent teaching, preparing for class, designing and reinventing ways to reach students' whole mind aptitudes. See generally Malcolm Gladwell, Outliers ch. 2 (2008) (describing "10,000 hour rule," where a study by Anders Ericsson concluded that 10,000 hours engaged in a given task (whether performing, swinging a golf club or programming a computer, for example) is a predicate to the sort of proficiency able to yield breakthroughs).

32 PINK, supra note 19, at pt. 1. 
(think artist or inventor)..$^{33}$ This paradigmatic game-change moves away from the "how to get from point A to point B" processes that characterized the last century's "information age" to the more innovatively conceptual "this is how A and B are related to and enhance the utility of X."

The mid to latter part of the twentieth century trumpeted the reductive and intensively analytical products of the "knowledge worker"-the computer programmers, the wielders of information and the "deployers of expertise." But globalization, outsourcing, technological achievement rendering obsolete entire categories of work, and sharp economic downturns are demonstrating the limits of the narrowly linear. In its place, the last two decades have witnessed the ascendance of the inventive, big-picture, "high concept" aptitudes. Those include the ability to see patterns, create meaningful narratives, and synthesize the seemingly divergent into cohesive wholes. Think about the synergy of the iPad/iPhone/iPod or the interconnectivity of Facebook and you get a feel for the power of the contextual and the simultaneous, hallmarks of a shift from linear information-giving to "convergence culture," ${ }^{\prime 5}$ where every concept is devised and marketed to be useful and relevant across multiple settings.

For example, e-mail is a manifestation of left-brain linear thinking. Organized along a sequential timeline, it gives little thought to context or topic. ${ }^{36}$ As such, many analysts and users complain that it embraces a model "that feels obsolete." Cast as "a way to communicate that hasn't kept pace with its users," ${ }^{38}$ it subjects users to volumes of unnecessary email without providing effective strategies for managing transmissions, sorting by levels of priority, or connecting by category. Finding solutions requires right-brain conceptual thinking that appreciates the nuances of electronic inter-connectivity (think of the increasingly seamless web that is Twitter, Facebook, SMS, Skype, LinkedIn, Tumblr, Instagram and Snapchat to name a few), discerns user patterns, and creatively problem-solves. Google and Apple each recently put forth their own right-brain attempts at fixes with, respectively, "Priority in-box" and the "V.I.P." tag as ways to sort transmissions, relate those to others, identify urgency and notify users

See id.

$34 \quad I d$. at 2.

35 Henry Jenkins, Convergence Culture: Where Old and New Media Collide, 2-3 (2006).

${ }^{36}$ Jenna Wortham, When E-Mail Turns from Delight to Deluge, N.Y. Times, Feb. 10, 2013, at B3.

Id.

$38 I d$. 
when a transmission comes in from a previously identified "important person." ${ }^{39}$ No doubt additional products of whole-brainstorming are on their way.

The shift in emphasis from left to right brain proclivities is manifested in all aspects of "convergence culture," a term of art coined by a media analyst to describe the new territory of interconnected and integrative circles of influence that have altered the way business is conducted, leaders are elected, and children are educated. ${ }^{41}$ Referred to as the way "every brand gets sold across multiple media platforms," ${ }^{22}$ convergence culture is a product of the sort of high-concept right-brain thinking that has considerable implications for the law school academy and the practice of law. Indeed, it may help to explain why the academy's traditional ways are failing.

Long-established law school pedagogy appeals principally to left mind skill sets, rooted in the logical and analytical. Law schools emphasize the "case method" as a way of reasoning through precedent. Since Harvard Law School's Dean Langdell implemented the tripartite system of law school education in the $19^{\text {th }}$ Century-the casebook, the Socratic Method and the hypothetical fact-pattern based exam $^{44}$ - most law schools have followed its essential protocol in the core curriculum. ${ }^{45}$

Thus, students are trained "to look for 'relevant' facts, to label the problem, and to provide the professionally accepted solution-a determination of the merits of applying a particular law or legal theory." ${ }^{\prime 6}$ We teach our students that the result of a case turns in principal measure on what this and other courts have said about analogous sets of facts. If previous court rulings in the jurisdiction

39 Id.

40 JENKINS, supra note 35.

41 Id.

$42 \quad I d$.

43 See generally Bruce A. Kimball, The Inception Of Modern Professional EDUCATION: C.C. LANGDELL, 1826-1906 (2009).

44 Id.; see also LAWRENCE M. FriedMAN, A History OF AMERICAN LAW (2d ed.) (1985) (tracing history of legal education in the United States, from the pre- 1870 textbook/lecture method to the post-1870 case method).

45 While Harvard Law School recently revised its core curriculum to include components on statutory interpretation and problem-solving, to give students an introduction to the demands of the regulatory state, those changes sparked criticism that "simply juggling and re-mixing the lineup of substantive courses for first years" does little to enhance practical learning. Cohen, supra note 15.

${ }_{46}$ Janet Weinstein \& Linda Morton, Stuck in a Rut: The Role of Creative Thinking in Problem Solving and Legal Education, 9 ClinICAL L. REV. 835, 848-49 (2002-2003). 
directly support one's set of facts, then victory is likely. But if the weight of precedent suggests a contrary result, victory is unlikely unless carefully applied logic can demonstrate persuasively why the instant facts are distinguishable.

Outside of isolated upper-class electives like Jurisprudence ${ }^{47}$ and "Law and __ contextual and multi-disciplinary settings in which the cases find themselves, how "the life of the law has not been logic, but experience, ${ }^{, 49}$ and how the law relates not only to the necessities but also the opportunities of the time, with its prevalent prejudices as well as potential to reinterpret old symbols and beliefs. Relevant intuitions of how those reinterpretations occurred previously and might again now, and how they relate to "prevalent moral and political theories, policies and business practices tend to be relegated to the backburner in the interests of covering "the material." In that regard, it behooves us to reassess what we cover and why we tend to cast our scope of information-providing coverage so broadly. Certainly, we must aim to equip our students with the baselines for subject matter conversancy and readiness in every course that we teach. But now is the time to rethink what that readiness means. If one of the answers is "to prepare our students for the bar exam," it bears note that the bar review courses quite effectively reduce the whole of required coverage for each bar exam topic to several hours of live or online lectures.

In the core and required curriculum, our pedagogical choices are apt to stay anchored in the comforts of habit, trumpeting the mainstays of left-brain reasoning as our students learn to sort, assess, and outline the weight of precedent. ${ }^{51}$ So much of what we do there exalts the deductive, the sequential, the logical, and the linear, all worthy parts

47 See Michael Ambrosio, A Moral Appraisal of Legal Education: A Plea for a Return to Forgotten Truths, 22 SeTON HALl L. REv. 1177 (1992).

48 Those include, for example, Law and Morality, Law and Social Justice, Law and Critical Race Theory, Law and Feminist Studies, and Law and Literature.

49 G. EDWARD WHite \& JOHN B. MinOR, Justice Oliver WENDELl HOLMES: LAW AND THE INNER SELF 149 (1993).

50 Justice Holmes observed:

The life of the law has not been logic: it has been experience. The felt necessities of the time, the prevalent moral and political theories, intuitions of public policy, avowed or unconscious, even the prejudices which judges share with their fellow-men, have had a good deal more to do than the syllogism in determining the rules by which men should be governed.

Oliver Wendell Holmes, The Common Law (Paulo J.S. Pereira \& Diego M. Beltran eds., 2011).

51 See Erica A. DeGroff \& Kalthleen A. McKee, Learning Like Lawyers: Addressing the Differences in Law Student Learning Styles, 2006 BYU EDUC. \& L.J. 499, 506 (2006). 
of the picture, but not the whole picture. We have our students study the line of precedent for a particular unit of coverage, usually sequentially, where we ask: What were the facts of the case? How did the court rule? Why? What are the strengths and weaknesses of the arguments advanced? How is this ruling distinguishable from what came before? Those sorts of inquiries must be supplemented to include consideration of the more integrative, interconnected, intuitive, empathic and holistic responses to the material at hand.

Right-mind teaching asks the questions rooted in the metaconceptualizations. It is integrative, by asking our students, for example, to read a group of cases as a whole and, before getting to the trees, talk about the forest. What are the threads that tie together this group? What are the essential commonalities and differences? It is interconnected when it considers the consequences of the judgments at hand for larger settings and the greater social good. How is this material a mirror of its times? Has it played a role as a catalyst for change, and if so, how so and to what effect? How does it relate to the socio-economic, political and cultural norms of history, and how do those relate to contemporary circumstance? It is intuitive when it seeks out not only the textual but also the sub-textual judgments that helped to ordain the outcomes studied. It is empathic when it asks, why should we care about this subject matter? Most essentially, it is holistic when it asks, what do we do with our understanding of this material?

Even the skills-based adjuncts to the traditional curriculum, now in place at most law schools and advanced by the American Bar Association (ABA), tend to place the customary "thinking like a lawyer" paradigm into a left-mind skills-centric protocol. As articulated by the $\mathrm{ABA}$, each graduate of an accredited law school should have most, if not all of the following fundamental skills: "(1) problem solving; (2) legal analysis and reasoning; (3) legal research; (4) factual investigation; (5) communication; (6) counseling; (7) negotiation; (8) litigation and alternative dispute resolution procedures; (9) organization and management of legal work; and (10) recognizing and resolving ethical dilemmas. ${ }^{, 2}$

52 Id. at 508. (citing Am. B. Assn. Sec. of Leg. Educ. \& Admis. to the Bar, Legal Education and Professional Development-An Education Continuum, Report of the Task Force on Law Schools and the Profession: Narrowing the Gap 7-10 (A.B.A. 1992)). 
As applied, many of those tend to be the tools of informationproviders, a category increasingly relegated to outsourcing and the kind of off-site management that e-discovery ${ }^{53}$ and other information technologies provide. Software allows basic legal procedures and, alarmingly, not so basic legal procedures to be accomplished using online self-help, at a fraction of the cost. A veritable army of websites promise, for example, to "make it easy to incorporate a business or form a limited liability company online," ", "provide the complete selfhelp guide to your real estate closing," online divorce without lawyer fees, ${ }^{, 56}$ or serve as "the one stop solution for LLP formation and finding all information related to LLPs." ${ }^{, 57}$ Increasingly sophisticated software applications continue to be developed to accomplish even more subtle left-brain tasks with precision, speed, and great economic efficiency.

Staying relevant against the backdrop of significant demographic, socio-cultural, and economic shifts that have altered the ways that the law is perceived, accessed and practiced requires that we re-think and re-brand the theoretical and practical skill sets that we teach. Our students' success upon graduation now depends as much on their creativity as on their analytical acumen. The academy does a good job honing the deductive, logical, and precision-based methods of legal inquiry and problem resolution. Those tend to be rooted in emphasis on past events (what did the parties do? how did the court rule?) and predictions for the future (what are the implications for the next case?).

By contrast, when it comes to nurturing present mindfulness and the more organically integrative, holistic and less narrowly deductive capabilities (the stuff of right brain aptitudes), the temptation (born of our left-brain biases) might be to roll our eyes, dismissing that skill set as anything but skilled. It is easy to write off the very constructs themselves-"organic, integrative and holistic"-as too "touchy-feely" a basis for curricular reform. After all, so many of us were drawn to

53 Electronic discovery, or e-discovery, allows for the exchange in civil litigation of information in electronic format. Elaborate computer programs extract and analyze evidence using digital forensic procedures that yield a document review platform. AdAm Cohen \& David Lender, Electronic Discovery: LAW AND Practice (2011).

54 See MYCORPORATION.COM, http:/ / www.mycorporation.com (last visited July 13, 2014).

55 See EsCrowHelP.COM, http:/ / www.escrowhelp.com (last visited July 13, 2014).

56 See COMPLETECASE.COM, http://www.completecase.com (last visited July 13, 2014); see also DIVORCESOURCE.COM, http:/ / www.divorcesource.com (last visited July 13, 2014); see also OURDIVORCEAGREEMENT.COM, http://www.ourdivorceagreement.com (last visited July 13, 2014).

57 See LLP ONLINE, www.llponline.in (last visited Sept. 10, 2014). 
the law precisely because of our left-brain proclivities. We tend to be sequential, textual, and analytical in our approach. We are not apt to think very much about how to teach (let alone, practice) in the nonlinear dimensions. Yet, in what may become one of the great ironies of our craft, the very prowess that got us here may be illequipped to keep us and our graduates here.

Hence, for the sake of our students' ability to enhance their chances for success in a shifting world, as well as our own continued relevance, it is important that we think about and talk about ways to fortify the metaphorically right-hemisphere abilities. Right-brain thinking involves the non-sequential cognitions that are able to interpret things simultaneously, appreciate context, and put isolated elements together to perceive the bigger picture. Those can be incorporated into the classroom dynamic, with "whole mind thinking" the goal. Using the left mind for analytic, textual, and sequential processing, the right mind can be accessed to facilitate the contextual patterns, synergistic convergences and interconnectedness of given subject matter to larger settings and even bigger contexts.

The assimilation of whole mind aptitudes paves the way for nonroutine problem solving skills and can help to produce the sort of "non-routine savants" able to assure their own relevance and success. Google coined the phrase "non-routine savant," and states on its hiring site that at the highest level, "we are looking for non-routine problem solving skills. ${ }^{158}$ Expecting applicants to be able to solve routine problems as a matter of course, "the non-routine problems offer the opportunity to create competitive advantage, and solving these problems requires creative thought and tenacity." ${ }^{\prime 59}$ Teaching to the whole mind makes that kind of creativity possible.

Appealing to our students' empathic pathways is particularly wellsuited in view of what we know about their demographic and learning preferences. Indeed, to better appreciate the nature and significance of conceptual teaching and convergence learning, our students may be our best teachers. They have come of age as consumers and participants of social media, heightened interconnectivity, trending and high concept technologies. An understanding of our students' demographic - the so-called Generation $\mathrm{C}$-helps to put into context our likely constituency's aptitudes and proclivities, and what we can learn from those.

58 See Jonathan Rosenberg, Our Googley Advice to Students: Major in Learning, GOOGLE BLOG (Jul. 15, 2008), http://googleblog.blogspot.com/2008/07/ourgoogley-advice-to-students-major-in.html.

Id 
Those who study generational traits refer to the demographic born between 1982 and 2001 as "Millennials." "Generation C" is the subset within that group of those born between 1982 and 1996. Very interested in deriving meaning from context, members of Generation $\mathrm{C}$ tend to "work in more creative industries with less rigid social structures." They depend on frequent feedback, having been raised with lots of instant input as well as the generous assurances of parents, teachers and coaches. ${ }^{62}$ Attracted more to the conversation than the one-way message, they prefer to actively co-create the given content of an exchange. The "C" stands for "connected" content creators, a designation ascribed to the group by the Nielsen Company because "[t]hey consume media, socialize and share experiences through various networking tools more than other age groups." ${ }^{33}$ Indeed, whether using social media sites to participate in discussions about culture, trends, current events and ideas, ${ }^{64}$ voting online on how a given advertiser's commercial should end, ${ }^{65}$ playing complex virtual video games with other players free of the traditional boundaries of time and space, ${ }^{66}$ building or adding to websites, customizing their Nike sneakers ${ }^{67}$ or creating blogs, this generational group "flock[s] to brands who allow them to take ownership of ideas." ${ }^{68}$ That inclination renders this demographic and the one that follows ${ }^{69}$ particularly likely

60 See generally William STRAUSS \& NeIl HowE, supra note 23.

${ }^{61} I d$.

62 See Pink supra note 26 and accompanying text.

63 Zoe Fox, Forget Generation Y: 18- to 34-Year-Olds Are Now 'Generation C', MASHABLE (Feb. 23, 2012), http://mashable.com/2012/02/23/generation-c/.

64 See, e.g., TwITTER, www.twitter.com ("Connect with your friends-and other fascinating people. Get in-the-moment updates on the things that interest you. And watch events unfold, in real time, from every angle.") (last visited Sept. 10, 2014); PINTEREST, www.pinterest.com ("Pinterest is a place to discover ideas for all your projects and interests, hand-picked by people like you.") (last visited Sept. 10, 2014); TuMBLR, www.tumblr.com ("Tumblr lets you effortless share anything. Post text, photos, quotes, links, music, and videos from your browser, phone, desktop, email or wherever you happen to be.”) (last visited Sept. 10, 2014); INSTAGRAM, www.instagram.com ("Instagram is a fast, beautiful and fun way to share your life with friends and family.") (last visited Sept. 10, 2014).

65 See, e.g., INQUISITR (Jan. 22, 2013), www.inquisitr.com ("Coke ad invites you to pick [an] ending."); USA TODAY (Jan. 28, 2013), www.admeter.usatoday.com ("[Y]ou pick the Audi Superbowl commercial.").

${ }_{66}$ Dan Pankraz,. Gen C (Sept. 24, 2011), http://www.slideshare.net/jshaw20/genc-by-dan-pankraz-1228108588460973-8 ("Gaming now dwarfs Hollywood.").

67 NIKE, http://nikeid.tumblr.com/ (offering "the premiere customization experience for Nike footwear, apparel and equipment").

68 Pankraz, supra note 66.

69 Those born between 2001 to the present are deemed by generational watchers "Gen Z" or "Digital Natives." Their common attributes are similar to those of their predecessors, but with an even heightened appreciation for interconnectivity. 
to grasp, practice, apply and enjoy conceptual teaching and learning.

\section{B. Conceptual Teaching: The Big Picture}

Whole mind teaching requires that we hone our students' textual and conceptual skills. We accomplish the former when we appeal to the linear, sequential, logical and analytical reasoning processes. The latter, more conceptual processes, by contrast, are at work when we help our students to move away from the page and come to see the big picture interconnectedness (the circle within circles) of the contexts in play. Those cognitive processes discern synergistic patterns and derive meaning from them, devising new ways to problem-solve and innovate. The neuroscience reveals that pedagogical approaches aimed at moving from left to right-mind directed proclivities and back again increase the brain's plasticity, forging new pathways that create enhanced aptitudes. ${ }^{70}$

The idea behind whole mind teaching and learning is to consciously cultivate a classroom environment where students, having studied and analyzed the weight of authority, critically assessing the logic applied (left-mind propensities), can develop a cohesive experience about its meaning and applications (right-brain processes) and a baseline of proficiency that integrates both contextually deductive and emotional intelligences (whole mind). Meaning is enhanced when students are helped to forge a narrative about the given subject matter, linking that story to the larger historical, cultural and socio-economic frameworks of which given cases, statutory and regulatory authority are just a part. Most essentially, proficiency is heightened when we present our classes with opportunities to weave together the theoretical, doctrinal, historical and more contemporary contextual threads by applying those strands to settings that feel real.

An array of pedagogical devices can help to trigger empathic and more holistic neural pathways to learning. Those include story-telling, whether based on the teacher or student's own experiences or depicted in a clip from a movie or documentary, actual or simulated client interaction where the client gets to tell the story that brought her here, the inclusion of multi-disciplinary referents and reading

Members of this group have enjoyed lifelong access to communication and media technology, hence earning them the designation "digital natives." See generally JoHN Palfrey \& Urs Gasser, Born Digital: Understanding the First Generation of Digital NATIVES (2009).

70 See generally JeFFrey M. Schwarz \& SHARON BEGLEY, THE Mind AND THE BRAIN: Neuroplasticity and the POWER of MenTal Force (2003). 
materials, ${ }^{71}$ role-playing, play through the use of in-class games aimed at helping students solve the puzzle of a given problem or contextual challenge, exercises such as "you be the teacher" (or client, judge, neighbor, adversary, CEO, competitor-the possibilities, aimed at helping students put themselves in another's shoes, are broad) or "tell me what you just heard me (or your classmate) say" (an opportunity to hone active listening skills and to reveal how what we think we have communicated may not be what the listener actually heard) or "what are you sensing right now?" (a chance to tune-in to the intuitions and visceral responses that a given context elicits, and then to test, learn from and use those).

In all courses, the introduction whenever possible of even abbreviated opportunities for in-class simulations, where for example students get to be the lawyer actually counseling, problem-solving or negotiating for a "client," or listen to an attorney's or the professor's experiences in the trenches with the material at hand, or themselves play the role of teacher, judge or story-teller, helps to access and fortify whole mind aptitudes. Subject matter acuity is deepened whenever empathic pathways to learning are activated because the brain's neurological receptors (known now as "mirror neurons" ${ }^{\text {") }}$ ) work to anchor not only the learning that is achieved by both participant and observer, but the experience of that learning achieved. It is one thing to be told or to recite back what the law is. It is quite another to experience it, whether by doing it oneself or, as science now confirms, by watching someone else doing it. ${ }^{73}$

To hone whole mind conceptualizations in my Property class, when we turn to landlord/tenant law, for example, I have the students read in tandem the case law on landlord's duty to deliver both legal and actual possession (a shift from an earlier, more agrarian system obliging the landlord to deliver to the new tenant only the legal right to be on site, relegating any holdover the new tenant's problem), landlord's duty to refrain from self-help, landlord's duty to mitigate when tenant vacates wrongfully with time left on a term of years lease, landlord's implied duty to provide inhabitable premises in residential leases and landlord's obligation to provide quiet enjoyment in all leases. At the time they were decided, each of those cases represented

71 See generally Paul T. Wangerin, The Problem of Parochialism in Legal Education, 5 S. CAL. INTERDISC. L.J. 441 (1997) (noting tendency for legal academy to decline opportunities for collaborative, interdisciplinary approaches to effective teaching).

72 See infra notes 78-81 and accompanying text.

73 See infra notes 78-81 and accompanying text on the discovery, in 1995, of mirror neurons, which allow us to feel as if we are actually doing what we are merely observing. 
a significant departure from precedent. Before we turn to the cases on an individualized basis, I ask the class to consider the common threads that tie those cases together and the shared catalysts that precipitated the courts' repeated retreat from the norm of stare decisis. Right-mind, big picture, high concept sensibilities are stirred as I ask the group to pay attention to the years in which each of the cases was decided, and to consider what else was happening in the law, as well as culturally, socially, economically and politically, at those times. Using their digital resources and appealing to their propensities for interconnectivity, I assign them the task of coming to class prepared to tell about the cases from that more expansive, contextual perspective and to find the metaconceptualizations that could have helped to predict those cases' outcomes.

As the students begin to think about the larger canvas on which the cases appear, and still in their right-minds, I ask them to be forward-thinking. To what extent do and should the conceptualizations that those cases share continue to inform landlord/tenant law today, and how might they help to forecast future trends? How did those cases, considered as a whole, shape future stocks of affordable housing? Is meaningful housing reform sustainable? Who should bear the costs of that reform? To what extent have enhanced tenant-protective judicial and statutory mechanisms prompted landlords to opt out of rental markets altogether, and at what price? What if all a tenant can afford is a substandard apartment? Is that at least preferable to homelessness? What do the cases and their consequences mean for us as lawyers and for the clients and constituencies that we represent? Here, still at the beginning of the unit, to access the more empathic gateways to learning, I present a five minute video excerpt of a recent nightly newscast on the new face of displacement and homelessness. The footage is compelling, jarring and able to add meaning and relevance to the material in ways that transcend the text.

As the class rises to the challenges of thinking about the material from a higher perch, students put the cases (which were decided in the late 1960s and 1970s) into the context of the larger cultural revolution of the time, where barriers to equality along race, gender and class lines were being aggressively challenged in a host of spheres. They link that time as well to one of increased urbanization, noting the demographic trends that found the vast preponderance of tenants dwelling in congested cities. They consider other simultaneous advances in the law, including the rise of consumer-protective statutes that endeavored to shield buyers of goods from unscrupulous 
merchant sellers and obliged those sellers to provide "merchantable" products. Those more integrative cognitions help the class to arrive at several unifying themes to tie together the cases.

First, the case law mirrors the larger socio-political temperament of its time, aimed at leveling playing fields and equalizing bargaining power. Through that lens, tenants were perceived, explicitly or sub textually, as underdogs whose interests needed to be protected. The cases reflect the shift away from what was once a landlord-protective posture to a far more solicitous tenant-protective model. Second, the urbanization of the time represented a significant departure from earlier, more rural demographic landscapes where, historically, the land was everything, with any structures atop the land merely secondary. By the mid-twentieth century, apartment dwelling was the norm, and tenants were bargaining not for the plot of land, but for the unit in a building atop the land. The parties' expectations as well as the judicial perceptions of respective rights and duties had to shift to more appropriately accommodate that reality. Third, against that backdrop, the symmetry of other statutory achievements (including the Uniform Commercial Code) helped to give courts a cohesive framework on which to move away from the perception of the lease as the grant of an interest in land to its present-day conceptualization as a contract, worthy of imposition of such contract-based formulations as the duty to mitigate, to provide a "merchantable" (i.e., "inhabitable") product, and to "cure" or repair defects on site.

As each of the cases is explored, I want the class to think about, see and get a feel for how the integrative, big picture conceptualizing that we did earlier (right-mind) can accommodate and assist with consideration of more fact-specific nuance (left-mind). Now, the group is called on to perform the left-mind's carefully precise, ordered and logical dissection of the materials. Then, to cultivate the whole mind aptitudes that allow students to work with the subtleties of the controversy before them to weave those into a compelling and cohesive narrative, the class is asked to problem-solve on behalf of various real and hypothetical clients. Introducing actual clients (this can be done in concert with the clinical faculty) or scripted "actors" whose dilemmas implicate relevant class materials, asking them to tell their stories, increases exponentially learners' whole mind skill sets. The cognitive science makes plain that when the pot of empathic neural receptors is stirred, we become more committed to the task of problem-solving. ${ }^{74}$

\footnotetext{
74 See infra notes 78-81 and accompanying text.
} 
Here, I introduce the class to "Danielle and Kevin," a fictitious couple (played by upper-class students) who are having problems with the apartment that they recently rented. I do not tell the class that Danielle and Kevin are actors presenting hypotheticals until the end of the segment. In repeating this exercise over the years, the level of class engagement and creative problem-solving is appreciably greater when the students believe that they are helping the couple out of a real life bind. In fact, at the time of this writing, having just concluded the vignette with my first year class, one of my students, particularly involved in helping to find effective solutions for the couple, exclaimed "I'm devastated!" on learning that the exercise was a simulation. When pressed, she added, "It felt so real and I wanted so much to help them, and I didn't realize how much I could help until I did." I explained that with those empathic pathways activated, that student (and, indeed, the entire class) became smarter, savvier and more earnest. I added that the group should look forward to the opportunities, in the near future, to experience on behalf of actual clients the sense of meaning and purpose that this simulation elicited. In the meantime, I encouraged the class to feel "Danielle and Kevin" in every case that they read, and to imagine the litigants as their clients or, at the least, as real people with real struggles and a story to tell.

"The big reveal," when I tell the class that the simulation presented was just that, a simulation, gives me one of several opportunities throughout the semester to deconstruct my pedagogical choices with the class. Letting our students know why we chose a particular teaching tool, why it works and how they can create comparable opportunities to enhance their own learning processes develops their metacognitions, or awareness of the actual process of learning itself. ${ }^{75}$ That awareness, in turn, allows for an internalization of the skills set, so that it can be applied in self-directed ways to future challenges. Making time at the end of each class and after class for collective debriefing is also exceedingly helpful in this regard. During debriefing sessions, as the class brainstorms on what the essential takeaways ought to be based on that day's scope of coverage, we take a few moments to talk about what worked for purposes of anchoring various constructs and where confusion lingers. Those metacognitions can be applied to the materials studied, asking what went right and what went wrong from the likely perspectives of the litigants and

75 See generally Paul T. Wangerin, Learning Strategies for Law Students, 52 ALB. L. REv. 471, 476-77 (1988) ("It is not enough for the student to be aware of his or her abilities and learning processes; the student must be able to monitor those studying activities during the learning process and be able to make appropriate adjustments.") 
litigators, how the parties could have found a better way out of the controversy at hand, and how less ego and more emotional intelligence might have led to different ends.

For purposes of the landlord/tenant simulation, I inform the class that Danielle and Kevin came to me for some guidance with respect to various problems that have arisen since they moved into their apartment. I indicate that I asked the couple if they would be willing to share their story with my class, and they gladly agreed. Now, much as an attending physician (that would be me) in a teaching hospital brings her interns (my students) on rounds to meet patients (the clients), hear their histories and then offer diagnoses and treatment protocols, I introduce the case and then have the clients tell their story.

First, the couple tells the class that they recently rented their first apartment and need to better understand their rights and duties. They ask if there is room to change any of the terms in the standard-form lease presented to them by landlord. The group thinks back to freedom of contract and its implications for these parties. The class asks to see the lease (waiting for that prompt, at that point I distribute copies), and then, with copies of the lease in hand, deconstructs its terms, seeking out potentially unreasonable or, again borrowing from the contracts-based conceptualization, unconscionable terms. For example, paragraph 14 of the lease displaces the implied warranty of habitability and limits tenants' damages for defective conditions on site. The class explains that in residential leases those clauses are unenforceable because they offend applicable public policy. Still, should counsel insist that they be stricken?

Danielle and Kevin then indicate that this month they had to purchase a space heater to keep the apartment warm. Immediately, hands shoot up with relevant questions that include, "Why did you need to do that?" (the apartment was without heat), "Did you notify the landlord" (by voicemail), "Do you have receipts for the purchase?" (yes), "What dealings have you had with the landlord in the past?," (he was very nice when he showed the couple around), "How many units does he lease?" (the building has twelve units), "In your estimation, is the landlord a good faith player who might be amenable to working things out?" (not sure). As the fact-finding continues, the class learns that a recent heavy rainstorm caused some flooding on site, requiring that the tenants remove their belongings from the bedroom. Still, the tenants would prefer to remain in possession (assuming that the problems with the premises can be remediated). 
The class advises the couple that the landlord has likely breached the implied warranty of habitability and additionally seems to have committed at least a partial constructive eviction (the diagnosis). The group then sets forth the tenants' remedial options, thinks about which of those are most likely to accomplish the tenants' goals and comes up with a plan of action (the treatment protocol). That protocol begins with (and endeavors to sustain) a non-litigious posture, particularly mindful of the tenants' desire to stay in possession, where the students are asked to call on their emotional intelligence to appeal to the landlord and, if available, landlord's counsel, as human beings apt to do the right thing if appropriately incentivized by the array of applicable carrots and sticks that might be wielded.

The opportunities to weave a narrative with recurrent characters like Danielle and Kevin are vast. (Interestingly, in subsequent visits, it tends not to matter that the class now knows that the narrative is fictitious. The neuroscience here suggests that the memory of the first experience with the couple allows for ready replication of that initial experiential response, so that the "as if" more easily feels real. ${ }^{76}$ ) The couple might "pop-in" for a quick ten-minute consultation to tell us that they wish to install a medicine cabinet in the bathroom, which presently is without one. Is landlord obliged to provide a medicine cabinet? If not, should counsel propose drafting an addendum to the lease that releases tenants from liability for any installations that tenants make, provided that tenants remove those at the conclusion of the lease and restore the premises to original condition, give and take ordinary wear and tear? Or is it better not to mention the intended installation at all? What is the ethical imperative here? What result now that the couple's houseguest trips on a loose floorboard, suffering personal injury? What of the recent break-in, perhaps linked to the deficient main entryway security system? The possibilities here are limitless, and can quite effectively provide opportunities for the class to discern the patterns at work, the interconnectivity of the law as it transcends subject matter categorizations and the moral referent that ought to guide the choices that lawyers make.

The notion of accessing whole mind integrative capabilities in the classroom is most apt to occur when we tap into our students' intellectual and emotional aptitudes. Certainly, some of what we do already in the core curriculum appeals to and fortifies our students'

76 See M.I. Posner \& M.K. Rothbart, Influencing Brain Networks: Implications for Education, 9 Trends Cogn. SCI. 99-103 (2005); See generally M.S. GAZZANIGA, R.B. IvvY \& G.R. Mangum, Cognitive Neuroscience: The Biology Of Mind (2002). 
empathic quotients, thereby paving the way for meaningful assimilation and application of the materials studied. For the most part, however, we may have little conscious awareness of when and how we accomplish that, and why it matters. Moreover, in the actual classroom we most likely do not do it enough. ${ }^{77}$ It becomes helpful then to render some of the implicit more explicit, focusing on ways that we might enhance opportunities in all classes for the kinds of experiential learning that can better equip our graduates for the challenges of an increasingly more conceptual age. To wield the tools for whole mind teaching and learning, it is helpful to understand more about the toolbox that many of those tools inhabit-our mirror neurons.

\section{Harnessing the Power of Mirror Neurons}

The task of engaging the whole mind is enhanced immeasurably by understanding mirror neurons and their importance to conceptual understanding. Discovered toward the close of the twentieth century by a group of Italian scientists, mirror neurons "fire" when we are engaged in a particular task and, most significantly, "fire" in the very same way when we are observing another engaged in that task. ${ }^{78}$ Essentially, the observer's neurons "mirror" the observed conduct as if it were being undertaken by the observer, who feels "and attributes to himself the same feelings and experiences as the person who is carrying out the action first-hand." ${ }^{79}$ The mirror neuron mechanism contemplates a construct of intelligence that is deeply affected by "interaction and learning by imitation."

Researchers at the University of Parma, in Italy found that a neuron in monkeys' brains would be activated whenever a monkey got hold of a peanut or opened its shell. In a groundbreaking twist, the researchers also discovered that the very same neuron would fire when the monkey observed another monkey or one of the scientists opening

77 Empathic quotients tend to be fortified most often in the course of our students' clinical experiences and during skills and methods components to the curriculum.

78 Lawrence Shapiro, Making Sense of Mirror Neurons, 167 SYNTHESE 439, 440 (2009) ("The discovery of mirror neurons is nothing short of the discovery of a new sense.”); see also Mirror Neurons: The Perspective of Pedagogy for the Third Millenium - Part I, Fondazione PATRIzio PAOletTi, http:/ / www.fondazionepatriziopaoletti.org/news/ 227/neuroni_specchio_il_punto_di_vista_di_pedagogia_per_il_terzo_millennio_pa rte_i.html?language $=2$ ("The discovery of mirror neurons allows us to understand how we perceive and understand others ...") (last visited Sept. 10, 2014).

${ }_{80} \quad I d$. 
a peanut. ${ }^{81}$ While the neurons fired when the monkeys observed a human engaged in the action, they were not activated when the monkeys watched an inanimate object replicate that action. The researchers found mirror neurons similarly at work in humans, allowing the human brain, for example, "to be activated by the perception of others' emotions expressed through the face, gestures and sounds," and to "instantly codify those perceptions in motoric terms." ${ }^{" 12}$ They concluded that the neural mechanisms at work can enhance learning because they allow for what the researchers called "empathic participation."

The study of mirror neurons explains in scientific terms the mechanics of empathy. More than a century ago, a German psychologist coined the term einfuhlung to describe the experience of putting oneself in another's shoes. ${ }^{84}$ Translated into English as empathy, it is "the act of projecting oneself into the object of a perception." ${ }^{\circ 5}$ Mirror neurons, the brain's mechanisms for making sense of external activity, ${ }^{86}$ internally simulate that activity as if the observer were performing it. Thus, "when you watch a tightrope walker, you can actually feel yourself inside her body balancing on the wire." 87

As the enablers of empathy, mirror neurons allow us to grasp the minds of others "by feeling, not by thinking." 88 Those empathic pathways to learning allow us to experientially understand concepts by observing them in action. For example, "assume you are watching a

81 Giacomo Rizzolatti \& LeONARDo FogaSsi, Mirror Neurons and Social Cognition, in OXFORD HANDBOOK OF EVOLUTIONARY PSYCHOLOGY (R.I.M. Dunbar \& Louise Barrett, eds., 2007). See generally V.S. Ramachandran, The Tell-Tale Brain: A Neuroscientist's QUEST For What MAKes Us Human (2011) (examining mirror neurons and other cognitive functions of the human brain, and positing that mirror neurons are to psychology what DNA is to biology); Mary Ann Becker, Step Away From the PowerPoint: Using Mirror Neurons to Enhance Student Learning in the Classroom, 19 THE LAW TEACHER 1, 39 (Fall 2012), available at http://lawteaching.org/lawteacher/ 2012fall/lawteacher2012fall.pdf. ("These mirror neurons are essential to the learning process because they are what allow students to build off of a professor's explanation of material.").

82 See supra note 56 at 227.

83 Id.; see also Marco Iacoboni, Mirroring People: The New Science of How We Connect With OTHERS (2008); Marco Iacoboni \& Marco Dapretto, The Mirror Neuron System and the Consequences of its Dysfunction, 7 NATURE 942 (2006).

84 Timothy P. O'Neill, Mirror Neurons, The New Neuroscience, and the Law: Some Preliminary Observations, 39 Sw. L. REv. 499, 503 (2009-10) (citing work of Theodor Lipps as detailed in Iacaboni, supra note 83 at 8,108$)$.

${ }^{85}$ O’Neill, supra note 84.

${ }_{87}$ See supra notes 78-81 and accompanying text.

87 O’Neill, supra note 84.

$88 \quad$ Id. at 504. 
soccer game and you see a player kick the ball. Mirror neurons will help you to understand what a kick is by firing-that is, activatingthose areas of the brain that would be responsible for kicking if you were actually the kicker." 89

The study of empathic participation reveals that the act of observing another in an experience allows the observer to conceptualize and develop a rubric for processing that experience as if it was the observer's own. ${ }^{90}$ For example, a child who has never experienced the taste of a lemon will viscerally and cognitively respond to its tartness by watching his mother bite into a lemon. ${ }^{91}$ A framework for the child's conceptualization of a lemon is thereby forged. Whenever we find ourselves mimicking the body language of the person speaking with us, our mirror neurons are at work. When we watch a cooking show, pretend-whisking in our mind's eye as the eggs are beat, our mirror neurons are engaged, giving us a platform for understanding. When we write on the board, our students' mirror neurons are triggered as they watch, imitate and integrate.

Similarly, empathic centers are accessed whenever we act our way into a feeling, by emulating the example of a person whose particular virtues or proficiencies we admire. Shakespeare understood this when he wrote, "Assume a virtue, if you have it not ... [f] or use almost can change the stamp of nature." Stated less elegantly, our mirror neurons help us to "fake it until we make it." The capacity our students have to mimic experientially all sorts of behaviors based on what they are observing reinforces the powerful place that we hold as their teachers. Both in and out of the classroom, we are constantly demonstrating not just how to think, but how to $b e$.

The research on mirror neurons reminds us that as teachers we are constantly modeling for our students, both in and out of the classroom. The vision that we embrace for our craft, and our place in it, accomplishes all sorts of signaling for the constituencies that we serve. Particularly now, when the very relevance of legal education is subject to challenge, it behooves us to remember and to communicate to our students why we chose this context, why we believe in the promise and the power of our craft, and why we love the law (no matter that on some days we ourselves may be "faking it until we make it"). In class and out of class, we ought to be treating the law as if we love it,

Id.

$90 \quad I d$.

91 Becker, supra note 81, at 39.

92 Id. (citing William Shakespeare, Hamlet Prince of DenMark 108 (George Pierce Baker ed., 1913)). 
and teaching from that springboard. The vision that we embrace for our work, and our place in it, should include a view of our profession's best self, as noble and honorable. It is a vision that finds us all healers. When our comportment lines up with that esteem, our students cannot help but follow suit. Stated most reductively, their mirror neurons will allow them to feel the love.

Empathy as a tool for conceptual learning is wielded whenever we communicate our passion for the subject matter and our emotional responses to the paths walked by the parties involved in the cases before us as well as the communities that are affected by that controversy's resolution. Our students quite literally begin to develop a "feel" for the material when their mirror neurons fire in response to our cues. Those empathic pathways, in turn, help to forge proficiency by fortifying perceptions of the subject matter's relevance ("this is why it matters") and significance ("this is what it means").

In the classroom, we make use of mirror neurons as pathways to learning when we cultivate the human touch. ${ }^{93}$ Our use of eye contact, gestures, postural signaling and other body language cultivates "immediacy," or our students' capacity to connect with and access our conversancy with the subject matter, helping them take steps toward making that mastery their own. ${ }^{94}$ Mirror neurons exalt teachers' roles as living, breathing, dynamically responsive three-dimensional communicators. They reveal that the medium of imparting information matters and that teachers matter, an encouraging sign that may spare the craft from the obsolescence that virtual worlds threaten.

The science makes plain that in the classroom, face-to-face time is important, with the research suggesting that we ought to rely less on PowerPoint and more on direct interaction with our students. ${ }^{95}$ For that matter, the research on how best to access and effectively use mirror neurons as pathways to learning makes a compelling case for limiting, if not banning laptops in class, mindful that student-teacher connectivity is very much a two-way street. ${ }^{96}$ Just as our students need

93 Becker, supra note 81, at 39.

94 Id. See Paul L. Witt, Lawrence R. Wheeless, \& Mike Allen, A Meta-Analytical Review of the Relationship Between Teacher Immediacy and Student Learning, 71 CoMM. MONOGRAPHS 184, 184-85 (2004).

95 Becker, supra note 81 , at 39.

96 See, e.g., Editorial Board, Ban Laptops in Class, The CHronicle (Feb. 26, 2013), http://www.dukechronicle.com/articles/2013/02/27/ban-laptops-class (noting that educational benefits of banning laptops "would be considerable," since laptops promote "disengagement while physically present in the classroom," and adding that "allowing laptop usage seems to be a form of giving up. Why convene class if students 
to see us, we need to be able to see them, and laptops get in the way, literally, of that face-to-face connection. Moreover, our students need to be able to see each other, without distraction, for systems of reciprocally meaningful exchange to occur.

Across the curriculum, we enhance our students' capacity to develop a more nuanced feel for the material and create their own pathways to conceptual understanding when we remind them of the complexities of the humanity and the humanness of our work. Our teaching can make plain that every case tells a story rooted in the triumphs and tragedies of the human condition. The idea is to humanize what can otherwise become a purely analytical and theoretical exchange. We access our students' mirror neuron learning centers when we quite literally embody the concepts we teach. Linking the subject matter to our own experiences in the practice and in life, having students tell their own stories of their encounters with the subject matter and telling the stories of the cases we teach as just thatstories-enhances our students' capacity to "get a feel" for the constructs in ways that more linear and purely analytical reasoning do not. That "feel" is the gateway to conversancy. It is at the heart of experiential learning, and the neuroscience tells us that it works in part because when our mirror neurons fire, shades of the other's experience become our own.

For example, in my Property class, to stir the pot of empathic pathways to learning at the start of our coverage of the modern day land transaction, I introduce the material by recounting the steps to my own first home purchase. I tell of finding the house of my dreams in vivid detail, to communicate the emotionality and excitement of the transaction, as well as the stakes involved. I then have one of my students serve as my counsel, to walk me through the terms of the land contract. I ask lots of questions, mindful of the magnitude of this purchase-indeed, the largest purchase that I am apt to make in my lifetime. During the course of that class, as we analyze the case law on point, I will frequently return to our simulation as I call my "counsel" with more questions. With so much on the line, as the client I am understandably nervous, and I check in with my "lawyer" often. Here, we get to address our professional imperative, as attorneys, to return our clients' calls (the most likely cause of client discontent is the attorney's failure to return the client's calls. Mirror neurons anchor the point because now, having put themselves in my shoes, the class can readily conjure up from their own emotive repertoire my feelings

are half-present, constantly disturbed by text messages, games and Facebook?"). Id. 
of frustration and worry, feelings that their responsiveness can allay.) My "lawyer" and the members of her "firm" are given the opportunity to trouble-shoot, anticipate road blocks and see that those are removed well in advance of any collision. Alternating between the theoretical and doctrinal to the practical and emotional, and crossing the bridge from the abstract to the "real," keeps empathic pathways open, enriches students' perceptions of the relevance of the material and enhances the kind of integrative, visceral understanding of how "it all works" that is palpable and applicable to all sorts of settings.

In subsequent classes, an actual title searcher comes in to recount how he searched the title to the property that I am about to buy, walking the class through each of the steps with so much multi-sensory detail that they can almost smell the mustiness of the shelves of the grantor-grantee index. ${ }^{97}$ He brings in copies of all of the deeds (or links) in the chain of title, and then lines them up just as he would in the hall of records. As the students watch, their mirror neurons simulate and integrate into their own memory bank the experience of searching title. That experience makes it easier for the class to understand later on the chain of title cases that we read, and to put those into a workable and applicable rubric. (Thereafter, the title searcher and I take a smaller group of interested students to the county hall of records, where we walk the group through an actual title search.)

Sometimes I will invite a building inspector or engineer to class, to tell my "attorneys" and me about the condition of the premises. That expert brings in floor plans and photos that reveal a structural infirmity with two of the basement's beams. I am devastated, particularly since I already signed the contract to purchase the home and have my heart set on it. I coordinate this vignette with class coverage of seller's duty to disclose latent, material defects. The class asks the expert lots of questions, to get to how outwardly discernible the structural problems were, whether repair is possible and, if so, at what cost, whether seller could or should have known of the problem and how the expert would advise that we proceed. I then ask the class, "How am I feeling right now, and how, if at all, should that inform your counsel to me?" The students' aptitudes here tend to be acutely accurate, as their empathic sensibilities coincide with and enhance their deductive reasoning skills. Creative and sensible solutions are

97 I facilitate the inclusion of sensory detail by asking questions that help to elicit the feel of the title-searching experience, encouraging the class to do the same. The title searcher actually did search the title to my home, bringing in copies of the deeds in the chain of title. 
forged.

\section{TOOLS FOR WHOLE MIND TEACHING AND LEARNING}

Tools for whole mind teaching and learning can be found by analogy to what Daniel Pink, a leading thinker on economic transformation and business strategy refers to as empathy, story, play, symphony and meaning. ${ }^{98}$ Each of those constructs can have an effective place in the law school classroom in partnership with the more linear and traditionally analytical capacities, to yield more fully intact, happier and meaningful learning experiences. The inclusion of pedagogical choices aimed at whole mind aptitudes helps our students to see patterns, portend outcomes, develop game-changing strategies, find and forge the relationships among seemingly separate and distinct legal, social, cultural and economic constructs, and perceive not just the forest but effective and rewarding pathways through it. When emotional intelligence is triggered, empathic pathways are forged, equipping our classes with a framework for finding meaning in the textual and making the theoretical real.

\section{A. Empathy as Pathway to Learning}

Our pedagogical choices can become a catalyst for new ways to facilitate our students' command of the subject matter when we hone their abilities to put themselves in others' shoes, including our own. In my Property and Commercial Law classes, I introduce "You Be the Teacher" segments, ${ }^{99}$ where students are asked to assume the professorial role to teach the material, preparing for a part of the class as if they were the professor. They are required in advance of class to think about the essential teaching points and meaning (both textually and sub textually) of the assigned cases, statutes and problem-sets, and how those relate back to previous class explorations and can help to inform our future scope of coverage.

You Be the Teacher allows students to do for themselves what they perceive their teacher to be doing when she prepares for class. Students are charged with thinking about how best to render difficult material both accessible and understandable, how to put the assigned

98 PINK, supra note 19. The author of several books, including DRIVE: THE SurPrising Truth About What Motivates Us (2009) and FreE AGENT NATION (2003), Pink has written extensively about work, technology, business and socio-cultural trends.

99 Much like television or online news programs, at the start of each class I place on the blackboard that day's "segments" of coverage. This appeals to students" "viewing preferences" and helps them to conceptualize "the big picture" and its various component parts. For further discussion, see supra note 27 and accompanying text. 
materials into a larger context, and how to help the class discern why the topic at hand matters. Significantly, most of the students who perform this exercise, standing in front of the room (usually at the podium), embrace a posture of confidence and expertise that far exceeds typical levels of participation. Certainly, this is in part due to the heightened degree of preparation, but I am convinced that a good part of the students' new found acumen is attributable to their empathic experience of being a law professor. Indeed, I find that some of my students, particularly the women, begin to mimic my cadences, inflections, and body language as they teach. ${ }^{100}$

The dynamic cultivated by You Be the Teacher triggers multiple empathic pathways for the actors, the class and me. The studentteacher is emulating proficiency, and thereby on her way to becoming more proficient. Simultaneously, class members are mirroring their peer's experience of becoming the teacher, enhancing their own understanding of proficiency. Meanwhile, I am putting myself in my student-teacher's position as she is putting herself in mine, heightening my understanding and awareness of what it is that my students perceive that I am doing when I teach, and how they perceive that I do it. What I learn from that process helps me to rethink and recast some of my pedagogical choices, yielding opportunities for critical reassessment and reinvention.

The variations of You Be the Teacherare vast. Sometimes, I will have students assume the role of the judge in the given case, or perhaps the plaintiff, defendant, counsel, disgruntled neighbor, mediator, or any of a range of players implicated by the matter under consideration. Again, empathic pathways become active when we engage the capacity to put ourselves in another's place. "What Are You Sensing?" is a classroom exercise that I use to appeal more expansively to my students' emotional intelligence. To heighten the group's awareness of the host of important nonverbal cues that might otherwise go unnoticed or ignored, I ask class members to report on what they are reading between the lines as a classroom dynamic is occurring. Sometimes, I ask the question when the energy level in the room has dropped or is particularly heightened, or I hear rumblings from a particular part of the room.

100 During or after class, as we debrief, I learn that the similarities, when they occur, were not meant to be impersonations, but instead a representation of what proficiency sounds like in the estimation of the student who served as teacher, another reminder of our power as teachers to model behavior. 
Relevant documentaries, videotaped narratives, news footage and films can be helpful tools to create context and meaning. For example, a colleague who teaches Health Law ${ }^{101}$ stirs the pot of empathy by having students watch powerful narratives, captured on video, that chronicle the abuses perpetrated at nursing homes. This leads to a discussion of how the current regulatory environment fails to encourage nursing homes to meet people's needs for care and connection. The class then engages in a discussion of how skilled but amoral lawyers create corporate shells that effectively leave no one liable when abuses and neglect lead to injury and death for elders. In his Administrative Law class, that colleague shows a documentary about the plight of immigrants that connects the students both to asylum litigants and to the struggles of decision-makers.

A colleague who teaches Family Law ${ }^{102}$ begins the materials on domestic violence by showing a clip from the documentary Hostages at Home, where a battered woman recounts that she never thought of herself as abused because she is white, middle-class and without children. The woman adds, "I thought only minority women, poor, with a million kids were battered." That excerpt makes the point more powerfully than a case or scholarly commentary could that violence cuts across race and class divides. It is moving because it presents a multi-sensory experience of the consequences of domestic violence.

Law schools' clinical offerings and skills-based curriculum are particularly effective at engaging students' empathic pathways. ${ }^{103}$ As students learn about, and actually experience client interviewing and client counseling, they come to know more about building rapport, fostering trust, and dealing with difficult client emotions. Our Skills

101 Prof. Frank Pasquale, Professor of Law at the University of Maryland Francis King Carey School of Law and formerly the Schering-Plough Professor in Health Care Regulation and Enforcement at Seton Hall University School of Law.

102 Prof. Solangel Maldonado, Professor of Law, Seton Hall University School of Law.

103 In Re-vision Quest: A Law School Guide to Designing Experiential Courses Involving Real Lawyering, 56 N.Y.L. SCH. L. REv. 517, 527 (2011), Deborah Maranville, Mary A. Lynch, Susan L. Kay, Phyllis Goldfarb, and Russell Engler write:

[T] he goals of experiential education have included engaging students, understanding unequal social structures, advancing social justice, developing lawyering skills, cultivating professional identity, fostering professional ethics, providing culturally competent client representation to a diverse array of clients, developing sound judgment and problemsolving abilities, gaining insight into law and the legal system, promoting lifelong learning, and learning to work collaboratively. 
Curriculum Director ${ }^{104}$ has students imagine what it is like to be the client and to anticipate how the client perceives the lawyer. She notes that this can be particularly challenging but necessary when teaching students about effective cross-cultural communication and how to connect with clients who may be different from them, either because of culture, class, race, gender or ethnicity, for example.

In the classroom, we wield empathy as a tool for conceptual learning when we share our own emotional responses to the paths that had to be walked by the parties involved in the cases that we teach. At bottom, integrative or conceptual thinking depends on the ability to empathize with and to discern the subtleties of the struggles that summon the adjudicative function. It bears noting that in the classroom we hone those abilities first when we remain aware of the struggles that so often accompany our students' learning processes. When we respond empathically to our own students' struggles, we help them to know how to extend that same generosity to each other, and then, to the clients and contexts that they will serve. Empathic teaching asks that we see our students as they are and as they could be. It requires an assiduous commitment to fusing technique and compassion. The legal realist Karl Llewellyn got it right when he observed, "Compassion without technique is a mess; and technique without compassion is a menace." 105

\section{B. The Power of Story}

Story is "context enriched by emotion."106 It is a particularly effective way to access empathic pathways to learning because it uses the power and importance of the narratives we present to teach cases in context. Story helps our students to engage in narrative imagining, opening up cognitive processing centers that can better assess the subject matter's relevance and significance. ${ }^{107}$ Moreover, by telling the stories of the cases we teach as we encourage our students to do the same, we weave together common threads with an emotional impact that enhances anchoring of the material. It is the emotional element that helps to make the material sink in. Stories "encapsulate into one

\footnotetext{
104 Prof. Maya Grosz, Director of the Skills Curriculum at Seton Hall University School of Law.

105 Roger C. Cramton, Beyond the Ordinary Religion, 37 J. LEgAL EdUC. 509, 510 (1987) (quoting Karl Llewellyn).

106 PINK, supra note 19, at 103 .

107 As conceived by a cognitive scientist, "Narrative imagining-story-is the fundamental instrument of thought.... . Most of our experience, our knowledge and our thinking is organized as stories." MARK TuRnER, THE LITERARY MIND: ThE ORIGINS of Thought AND Language 4-5 (1996).
} 
compact package, information, knowledge, context and emotion," ${ }^{108}$ honing our students' abilities to conceptualize of and present materials cohesively and compellingly. Whole volumes are now available for each of the core courses in the law school curriculum to help us to tell the stories of the particularly seminal cases that we teach. $^{109}$ That story-telling should be more the norm than the exception.

When we teach our students to be persuasive story-tellers of the law as it applies to facts, we afford them a skill set that is not apt to be supplanted by technological advance or outsourcing. While factfinders, whether virtual or real, are mere information-providers, storytellers are artists. When I ask a student to tell the class about a given case, I ask that student to tell us the story of the case. Often, I ask that student to tell the story as the narrator of a movie or play might tell it. Then I ask the class to tell me, in view of the case's outcome, how they think the respective litigators must have told the story. How could a better story have been told? I aim to help my classes to see that how we tell the story of a given controversy can ordain its outcome.

While advocacy courses teach students about the importance and mechanics of good storytelling, ${ }^{110}$ the device can also be demonstrated and deconstructed to great effect in first year and upper-level courses, both required and elective. Further, when we link the subject matter of the courses we teach to our own or others' practice-based experiences, we use story to build context, thereby helping our students to cross the bridge from theory to practice. By putting the material into its applicable settings by telling of our own encounters with it, born of our time in the trenches or as a product of our living life, we allow our students to get an intrinsic feel for the material that yields the sort of connection-making that textual study alone cannot achieve.

108 Don Norman, Things That Make Us Smart 146 (1993).

109 See, e.g., Property Stories (Gerald Korngold \& Andrew P. Morriss eds., Foundation Press 2004).

110 For example, under the direction of its very talented Skills Curriculum Director, Professor Maya Grosz, Seton Hall University School of Law's Persuasion and Advocacy classes hone students' storytelling abilities by requiring them to craft persuasive theories for the given case, develop creative labels that paint a picture of what happened in a light most favorable to their client, and use themes to weave together divergent strands into a whole fabric. During the very first class, Prof. Grosz tells her students that lawyers are storytellers, and that "the most successful lawyers are those who tell the most compelling stories." 
For example, a colleague has his Business Associations class ${ }^{111}$ read the case law and relevant statutory authority on oppressed minority shareholders' rights and then, from that doctrinal and theoretical springboard, he tells the story of his own personal experiences dealing with break-ups of all sorts of businesses involving abusive treatment of minority owners by control owners (most dramatically in the context of bitter family battles that usually involve siblings). When he teaches Constitutional Law, he brings the Establishment Clause to life by drawing on his experiences representing a public high school football coach who sought to vindicate his players' right to say a pre-game prayer.

A colleague who teaches Criminal Law ${ }^{112}$ shares with her classes from the repertoire of her experiences as a former public defender, to get students to think contextually about the concepts that they are studying. Those experiences are often emotionally compelling, gutwrenching, and catalysts for the group's assessment of a myriad of textual and also sub-textual issues. For example, when studying the requirement that there must be an "act" (or omission of an act) to impose criminal liability, she asks the class whether there might be instances where what qualifies as an "act" is more akin to a thought, thereby triggering first amendment values. She then tells the group about a case that she had worked on where her client was accused of possessing virtual child pornography. The images in question were undoubtedly disturbing, but also unquestionably "virtual." They were computer-animated and could not have been mistaken for actual children. Was possession of those images a criminal "act," and might there be good public policy reasons militating against its criminalization? From that discussion, the class moved on to consideration of the social harms in play and how best to prevent those.

Story can utilize metaphor and analogy to great advantage. Both help students to relate new and unfamiliar concepts to more familiar contexts, thereby enhancing their comprehension, retention and, perhaps most of all, calm. ${ }^{113}$ They help our classes to use what they

111 Prof. Ronald J. Riccio, Professor of Law and Dean Emeritus, Seton Hall University School of Law.

112 Prof. Jenny Carroll, Professor of Law at the University of Alabama School of Law and former Professor of Law at Seton Hall University School of Law.

113 See generally GeORGe LAKOFF \& MARK Johnson, Metaphors We Live By (2nd ed. 2003). Countless studies reveal that performance is enhanced immeasurably by calm. For a compilation of the science on performance anxiety, see SIAN BEILOCK, CHOKE: What The Secrets of the Brain Reveal About Getting it Right When You Have To (2010). 
already know to understand what they have yet to know. As effective teaching strategies, metaphors and analogies trigger neurological "visualization" sites, thereby experientially rooting the material at hand. ${ }^{114}$

For example, in Property the law of servitudes can be bewildering, in significant part because similar-seeming interests are treated as separate and distinct, accompanied by their own rules for formation and transferability. To introduce the material, I ask the students to imagine that we are now in an enchanted forest ${ }^{115}$ where each of the trees and botanical species that we encounter represent a type of servitude. While each is separate, all are part of the same habitat. First, we see the mighty redwoods. Those are the easements, the most formidable of servitudes. They are deeply rooted and usually enjoy permanence on the land (in the way that the easement passes automatically with the land). Further away, we observe in stark contrast to the mighty redwood mere saplings, akin in appearance to the "Charlie Brown Christmas tree." Those are licenses, the flimsiest of servitudes. The license can topple at any time because it is freely revocable, at the will of the licensor, unless estoppel applies to bar revocation. A distance later, we find fruit trees. Those represent profits, a form of servitude entitling its holder to enter land and take from it some product of the soil. We pick a few pieces of fruit as a profit-holder might and move on to encounter azalea bushes, each flowering in different colors. Those represent the covenants, a part of the habitat that is very different from the trees just encountered. Covenants begin as contracts, not property interests. The azaleas come in a multitude of colors, reflective of the many shades of covenants that landowners might choose to enhance land use and enjoyment. Nearby are the hydrangeas, the equitable servitudes. They are like the azaleas (both are flowering bushes), yet different. While there is significant factual overlap between covenants and equitable servitudes, those two forms of servitude are separate and distinct.

When we get to the often dreaded system of estates and future interests, I ask the class to imagine those interests existing inside a vast English Tudor mansion. As we enter the first floor of this house of learning, the rooms are labeled and furnished to represent each of the four present possessory freehold estates. On the second floor, we find the future interests. There, remainderman becomes a living

114 Randy Garner, Humor, Analogy and Metaphor, H.A.M. it up in Teaching, 6 RADICAL PEDAGOGY (Winter 2005), available at http://www.radicalpedagogy.org/radical pedagogy8/Humor,_Analogy,_and_Metaphor_H.A.M._it_up_in_Teaching.html.

115 I ask the class to work with me here. 
personality, as does his sinister distant relative, the executioner (or holder of an executory interest). I pull out the essential attributes of those interests by telling (and having the class add to) the story of those characters and their extended family members' lives (in the form, for example, of the timid contingent remainders, the more confident vested remainders and the bouncy springing and crafty shifting executory interests).

\section{Using Play to Enhance Whole-Mind Teaching and Learning}

Play is an important adjunct to the use of story. It can help our students to become a part of the story. Play is something we do in class when we use games, puzzle-solving and role-play as forms of investigation. As its name suggests, it is supposed to be fun as it accesses the more kinesthetic and interactive learning pathways. ${ }^{116}$ I use play, for example, in my Commercial Law course when we explore the parole evidence rule, a difficult provision that allows final contracts to be supplemented by evidence of consistent additional terms but prohibits the admission into evidence of contradictory proffers. The rule endeavors to protect writings entered into with care and finality, shielding them from contradiction by evidence of what allegedly transpired before final integration. Still, while final writings cannot be contradicted, they can be supplemented by consistent terms and by relevant custom.

To illustrate those tenets, I distribute problem sets, work through relevant cases and have the students engage in some group drafting of effective merger and disclaimer clauses. Always, I see that some class members continue to struggle with the rule and its applications. To move the class away from the page, here I include a segment where I ask a volunteer to come forward. I ask the class to imagine that the volunteer is a "contract," and that each item of clothing and every accessory that $\mathrm{s} /$ he is now wearing represents a contract term. We imagine that we were all parties to the formation of this "deal." I ask the class to assess the "living contract" to determine whether or not it seems to be at least partially integrated or sufficiently "final" to be worthy of parole evidence rule protection. In other words, how carefully put together is this three-dimensional representation? This becomes a visceral and visual determination, akin to the "you'll know it when you see it" approach. Most often, the class concludes that the

116 See generally ROBERT EPSTEIN, CREATIVITy GAMES FOR TRAINERS: A HANDBOOK OF GROUP ACTIVITIES FOR JUMPSTARTING WORKPLACE CREATIVITY (McGraw-Hill 1995) (describing the effectiveness of game-playing to build community, creativity and connection). 
"contract" is at least thoughtfully constructed enough to be worthy of protection from contradiction.

Now I ask the group to assume that matters have become litigious, and that one of us seeks to introduce evidence to the effect that, for example, we had actually talked about and intended to include a "hat term" in the deal. The "contract" standing before the group does not include a hat term. I then actually place a hat on the "contract." Sometimes it is a baseball cap. Other times, it may be a fedora, a cowboy hat or a sombrero. Would evidence relevant to the alleged determination to include a hat term be admissible? It depends. I ask the class to once again take a look at the deal that we struck. Does the proffer in my hand seem to be a consistent additional term? It may be, if it is a baseball cap and our "contract" is garbed in typical student attire, but it won't be if it is a cowboy hat, unless for example our contextual setting puts the "deal" on the range or on a farm. The latter possibility reminds the class of the importance of assessing contracts in context, never divorcing a deal from its commercial setting.

Next, I place other "contract terms" (a belt, cufflinks, a t-shirt, sunglasses, a backpack) on the table in front of the class, and ask for volunteers to come down, pick a term and make the case for its admissibility or inadmissibility into evidence. For example, the student who selects the t-shirt term will likely argue against its admissibility, mindful that it contradicts the button-down shirt term that our contract is already wearing. Final deals should not be contradicted. Otherwise, what would be the point of entering into contracts with finality and care in the first place? Then, that same student makes the case for the shirt term's admissibility, by arguing, for example, that it is a consistent additional term, meant to be worn as an undershirt, in accord perhaps with our past practices. Thereafter, a student makes the case for the introduction into evidence of the sunglass term. Our deal is not wearing sunglasses. Hence, the term seems to be a consistent additional term, unless our contract is so meticulously and fully integrated as to be "final, complete and exclusive." The game continues as I ask students to attempt to supplement or seemingly contradict the terms of our "contract" by seeking to introduce a few more proffers, with each vignette anchoring a particular nuance of the rule and providing a basis for better understanding its rationale and context.

In Property, I toss a baseball into the assembly (gingerly and with poor aim) to get to the uncertainties of the rule of capture, as one student seems almost to have caught the ball until another student steps in or the ball drops to the ground. To assess the dubious 
assumptions that underscore the law of finders, I plant items around the classroom that will be "found" during class, asking the finder to try to presume the true owner's intent (was this item lost or mislaid?), a typically impossible task. In all of those instances, play incorporates multiple learning modalities, from the visual to the kinesthetic to the auditory. ${ }^{117}$

Sometimes, I will have students write mini-scripts or devise "dramatic re-enactments" to get to various constructs and their applications. For instance, in my Property class, students wrote and acted out Porch Story, which involved the saga of a client who sought permission to build a glass-enclosed front porch to help abate his child's allergies. The proposed porch offended the local minimum setback requirements, necessitating an application for (and eventual grant of) an area variance. Thereafter, a tale entitled It Is About the Bike introduced the class to a cyclist who was just fined for violating his residential development's "no cycling" restrictive covenant. The possibilities here are vast and can touch on lots of larger concerns (for example, the "no cycling" rule offends environmental and wellness sensibilities and could be exclusionary by shutting out those without a car).

Play can also include music and song. Both are effective educational tools because music activates the sorts of neural firing patterns that simultaneously connect multiple brain centers. Those synchronized firing patterns enhance retention (something that Madison Avenue advertisers have intuited for decades. Think about the jingles that you can still recall even from years ago). Because it is such a potentially powerful neurological stimulant, music can also trigger the higher brain functions, such as creative problem-solving. ${ }^{118}$

In class, sometimes I have students come up with jingles and rhymes to anchor various constructs. For example, in Commercial Law, I ask the class to devise a rhyme, set to a rhythm or melody, to get to the essence of how best to gauge quantity in requirements and output contracts under Article 2 of the Uniform Commercial Code. Samplings of what comes back include "what do you require buyer?" (the requirements contract), "if you make it, I'll take it" (output) and "what will the giver deliver?" (output). Those rhymes become

117 See generally Paula A. Franzese, Strategies and Techniques for Teaching PROPERTY (2012) (setting forth pedagogical approaches to subject matter, mindful that students learn in different ways); Robin Boyle \& Rita Dunn, Teaching Law Students Through Individual Learning Styles, 62 ALB. L. REv. 213 (1998) (charting student learning differences and effective incorporation of multiple learning modalities).

118 Eric Jensen, Musical Arts Make Sense!, SONGS FOR TEACHING (2002), http://www.songsforteaching.com/ericjensen/2.htm (last visited Sept. 30, 2014). 
cemented and help the class to identify the requirements or output contract later on when they see it again.

In Property, I invoke the Motown classic "It Takes Two" to get to the hallmark of the easement appurtenant, where two parcels of land must be involved. (One derives the benefit of the easement, and the other bears the burden of the easement). I assign students to create multi-sensory renderings of some of the cases and some of the bigger concepts. For example, I ask a team to collaborate on a field project, dispatching them to take photos of the servitudes in their neighborhoods. The group puts together a PowerPoint showing the products of their search and characterizing each of the entitlements that they perceived. The presentation includes a soundtrack and interactive questions so that the class can weigh in on how they think the interest presented ought to be classified.

\section{Using Symphony to Appreciate Interconnectivity}

Much like its musical referent, symphony is the composition we create for each day's scope of coverage. As I prepare for class, I think about how the material is both part of an integrated whole as well as separately compartmentalized. At the start of each class, once the students are seated and ready, I use the board to present an outline of that day's "composition," placing the title of the given "piece" (i.e., unit) up on top and then dividing it into various "movements" (segments of coverage). If more than one unit or topic is to be covered, I build in an "interlude" to make the transition by linking relevant refrains that came earlier to what is about to come. As I teach, I often think of the class as the members of the orchestra. Each will be making a contribution, sometimes perhaps off-key but always capable of fine-tuning. I am the conductor. It is my job to lead, make transitions seamless and elicit the best from my musicians.

Using the board to present an outline for each class can be more effective than using PowerPoint to do the same because as students watch their professor generate the diagram in real time they are simulating both the act of writing and creating. ${ }^{119}$ Further, building finite "segments" into each class and sharing them with the group at the start facilitates conceptual learning. By helping students to see the big picture and its constitutive parts, we give them a platform from which to even more expansively relate and connect the constructs in new ways. Moreover, the "segment" approach adds predictability, helping students forecast where we are headed, and, by indicating how

\footnotetext{
119 See Becker, supra note 81 and accompanying text.
} 
much time will be allotted for each segment, setting the expectation that when time is up, we move on. Finally, borrowing from what news producers know, using timed segments and showing at the start what those are appeals to media consumers' (our students') "viewing preferences," allowing them to begin connecting the dots, know what to look forward to and how to comport their behavior accordingly.

Symphony speaks to the ways that we enhance our students' aptitudes to see and find connections, even between settings that superficially seem unrelated. It engages the capacity to perceive correlations by linking together seemingly disparate elements. At bottom, "[s]ymphony is largely about relationships." ${ }^{20}$ It is particularly appealing to multi-taskers (i.e., our students ${ }^{121}$ ), who are interested in and are usually very good at applying their repertoire of talents and range of conversancy in ways that can relate a particular context to others, sometimes reinventing the given construct in the process. ${ }^{122}$ For example, in Property, a student who majored in American history as an undergraduate linked the concept of partition to systems of subjugation, most specifically to the detriment of low-income black farmers. Another student, a socio-linguistics major, helped the class to see how courts' use of language can even unconsciously send all sorts of messages. An urban studies/architecture major presented a compelling PowerPoint on how wondrous designs that defy convention would have been stymied had zoning laws had their way. Symphony encourages those sorts of integrative and interdisciplinary inquiries.

Our students want to learn how what they already know relates to what they are now studying. Symphony provides us with the opportunity to appeal to and effectively use our students' diverse educational backgrounds to see how the law can fit into and draw upon those experiences to create meaningful outcomes. It facilitates a kind of holistic synthesizing, so that the law is seen not as separate from the social and natural sciences but instead as part of a much larger world order, where it can be both mirror of a certain status quo and catalyst for reform. Consideration of the multi-disciplinary connections at hand helps to prepare our students to problem-solve in ways that transcend the purely legal. ${ }^{123}$

120 PINK, supra note 19, at 134.

121 See Grosz, supra note 110 and accompanying text.

122 Think about how Millennials have re-invented pop music, making the old new again by sampling hooks of earlier hits, electronically re-framing them and linking them to new melodies, and you have another metaphor for symphony.

123 See generally Janet Weinstein, Coming of Age: Recognizing the Importance of 
Students lament the pigeonhole that they perceive law school education to be. They come to us already learned in particular spheres and yearn to know how that conversancy fits into their emerging understanding of the law. Their assigned readings seldom depart from the casebook, statutory authority and law review articles, and their inclass experiences are often perceived as limiting. I first noticed this perception years ago, when, as an introduction to the advent of zoning in my Property class, I began to describe the socio-political landscape of early twentieth century New York. Waves of immigrant workers, able to find employment only in factory sweatshops, began living near those factories in newly-created and squalid tenements, so that they could quickly walk to and from work. An unintended consequence found those "undesirables" now dwelling in relatively close proximity to the more privileged classes, who deemed their new neighbors "repulsive." Those upper echelon citizens prevailed upon the mayor and political machine (whose favor had been bought) to "do something" to eradicate the "nuisance" in their midst. Hence, zoning came to New York as a way to relegate and classify uses to insure that the "wholesome, highest and best uses" (the townhouses inhabited by the likes of the Rockefellers and Vanderbilts) were kept protected and away from the less desirable uses (multiple-family dwellings, apartment buildings, commercial and industrial uses). Discussion came alive as the students, drawing upon their own conversancy with history, sociology, anthropology, economics and political science, began not only to contextualize zoning but also to critically reassess and recast its aims.

\section{E. Meaning as Pathway to Purpose}

Meaning is the quest to find purpose in the process of learning and then practicing the law. It is enhanced when the classroom experiences that we cultivate help our students to remain vigilantly mindful of the promise of our craft and their place in it. As my colleague Shavar Jeffries has said, "There can be no justice without just lawyers." ${ }^{24}$ Teaching with meaning aims to deliberately infuse each class with strands of the ethical and moral imperatives that inform justice and that build just lawyers.

Interdisciplinary Education in Law Practice, 74 WASH. L. REV. 319 (1999).

124 Prof. Shavar Jeffries, Orientation Address to the Entering Class at Seton Hall University School of Law (Aug. 20, 2011), available at http:/ /law.shu.edu/Prospective Students /New/loader.cfm?csModule=security/getfile\&pageid=144129. 
Teaching is a moral craft, requiring that we endeavor in all courses to communicate core values of ethics and professionalism. We help our students find meaning when we engage them in theoretical as well as practically applied considerations of right and wrong, of prudence and fairness, and of the struggles of the people behind the cases. In his recent Orientation address to Seton Hall Law School's entering class, a senior faculty member put it this way:

We need lawyers with inner integrity and outer authenticity: lawyers who are self-constituted, self-possessed and selfrealized; lawyers who understand that law has moral value, that the authority of law depends on its ability to secure justice, that individual lawyers and the legal profession bear special responsibility for promoting truth, justice and the common good. ${ }^{125}$

We provide pathways to meaning when we communicate to our students by words and actions the importance of heeding the call to service and when we help them to find ways to promote the common good. ${ }^{126}$ Time and again I remind my classes that the surest way out of our own pain is to help others find ways out of theirs. ${ }^{127}$ Particularly now, when so many are denied access to the law because of poverty or circumstance, there has never been a more important time for us, the lawyers, to enter the fray.

Meaning is enhanced when we give our students opportunities to see how theory can be put into practice. Mindful that "you can't be what you can't see," in my first year Property course I encourage my students to see what can be done to do well and also to do good with the predicates that we establish in the classroom. Conceptual teaching aims not only to instruct, but also, to show. For example, students might spend a Friday afternoon in landlord/tenant court and then sign up to do pro bono work on behalf of indigent tenants. They might shadow a real estate lawyer on a closing and then accompany that

125 Prof. Michael Ambrosio, The Moral Dimension of the Law, Orientation Address at Seton Hall University School of Law (Aug. 20, 2012), available at http://law.shu.edu/About/News_Events/Program_Highlight/program-highlightspotlight.cfm?customel_datapageid_4661=303893.

${ }_{126}$ Raymond Brown, Jr., a human rights lawyer, recently cited to my Property class the observation that "a lawyer who is not in some way an agent for social change is a parasite." Raymond Brown, Jr., Remarks delivered at the Loving the Law Day Celebration (Feb. 15, 2013).

127 See Paula A. Franzese, From Tragedy, Hope: The Good Lawyer and the Pursuit of the Public Interest, 32 Seton Hall L. Rev. 451, 453 (2002) (“As lawyers, we are public servants. We are not automatons, technicians or hired guns. We are people, representing people in need. When we gauge each other's measure, service, integrity and that commitment to people should be what counts."). 
lawyer to one of the sites of Hurricane Sandy's devastation to help distraught homeowners through the web of legalities that attend the rebuilding process. They might conduct a title search in the county hall of records and learn how that system can protect the vulnerable and the elderly against fraudulent conveyances. For each of the units that we cover, I provide the class with the names and contact information of alumni who practice in that particular field and who are willing to be mentors to show interested students what they do, how it is relevant to what the class is studying and how they derive meaning from the work that they do.

Enhancing meaning is a nuanced task that gets students to think about and talk about how to deal with moral issues, particularly when they seek to do the right thing in contexts where that impulse is not exalted. Elements that value winning at all costs can quickly devolve into an "if it is legal, it is ethical" mindset. ${ }^{128}$ We need to be reminding our classes that just because one has a right to do something does not mean that it is the right thing to do. ${ }^{129}$ Here, I ask my students to think about their first principles. What do they stand for? What are their "non-negotiables"- those values and virtues that they are not willing to compromise? I share my own answers to those questions and ask guest speakers to share theirs.

Every week I build into class coverage a segment called "The Good Lawyer." During that segment, I present a hypothetical that builds on the material at hand by presenting an ethical dilemma for the lawyer and her client. For example, in my Commercial Law class, when we cover the statute of frauds in the context of Article 2 of the Uniform Commercial Code (governing contracts for the sale of goods), we consider the admissions exception to the writing requirement. ${ }^{130}$ That exception provides that one does not need a writing to authenticate the existence of a deal when the party against whom enforcement is sought admits to it in sworn pleadings. ${ }^{131}$ What do you do, I ask, when your client comes to you and indicates that an oral contract was struck

128 See generally Paula A. Franzese \& Daniel J. O'Hern, Sr., Restoring the Public Trust: An Agenda for Ethics Reform of State Government and a Proposed Model for New Jersey, 57 Rutgers L. REV. 1175, 1234 ("Leaders deal with moral issues, many of which are not particularly valued by those elements of our society that emphasize competition and winning at all costs.").

129 See generally Oliver Wendell Holmes, The Path of the Law, 10 HARv. L. REv. 457 (1897) ("If you want to know the law and nothing else, you must look at it as a bad man, who cares only for the material consequences which such knowledge enables him to predict, not as a good one, who finds his reasons for conduct, whether inside the law or outside of it, in the vaguer sanctions of conscience.").

130 U.C.C. $\$ 2-201$ (West 2014).

131 Id. 
but that, since "nothing was ever put in writing," he is off the hook? First, the class has an opportunity here to recall the very purpose of the statute of frauds, which endeavors not to bar the enforcement of oral contracts but instead to prevent the fabrication of deals never actually struck. Second, the admissions exception to the writing requirement means that the client, when deposed, would either have to lie under oath about the existence of the deal (thereby perjuring himself) or answer truthfully that a deal was struck (thereby negating the statute of frauds as a defense to its enforcement). The attorney who is complicit in the client's telling of a lie has suborned perjury, an offense that can lead to disbarment as well as civil and criminal sanctions.

As our students find themselves serving in arenas that transcend the purely legal, they will need to know how the precepts that guide attorney professionalism can inform other settings' "best practices." In these increasingly interconnected times, our graduates will wear several hats, whether as corporate compliance officer, company executive charged with overseeing human resources, liaison to international operations, or any of a number of variations on intersecting circles of influence. They will be called on to exercise good judgment, a task that requires discernment. Our students come to better understand what that is when we call it out as we see it, in the behaviors and decision-making at play in the materials that we teach and the classroom exchanges that those materials inspire. Moreover, in all classes we need to be consciously engaged in the task of inoculating what we communicate with healthy doses of the sort of common sense and comportment that enjoys universal appeal.

We engage in conceptual teaching aimed at enhancing meaning when we ask our students to think about the big questions such as, what is the kind of society in which we wish to live? In these times of "market triumphalism," ${ }^{32}$ where markets have invaded virtually all domains, where do markets actually belong and, if they have exceeded appropriate bounds, how do we keep them in place? In my Property class, for example, we talk about how markets alter housing, and thereby civic engagement, friendship, and education and think about whether commercialism erodes community. For instance, the gates and walls that privileged classes can now live behind diminish the prospects for people from different walks of life to encounter one

132 See Michael J. SANDEl, What Money Can’t Buy: The Moral Limits of Markets 202 (2012) ("The era of market triumphalism has coincided with a time when public discourse has been largely empty of moral and spiritual substance. Our only hope of keeping markets in their place is to deliberate openly and publicly about the meaning of the goods and social practices we prize."). 
another. ${ }^{133}$ As the gaps between economic groups widen, "the marketization of everything means that people of affluence and people of modest means live increasingly separate lives."134 Is that a satisfying way to live? What does that mean for democracy?

Meaning is forged when we remind our students of the value of precedent but also of our imperative to work to change bad laws. For example, one colleague helps her students to understand the role of lawyers and the importance of advocacy when she teaches, in Evidence,${ }^{135}$ of the previously entrenched exception to the hearsay rule for excited utterances and the ways that it offends constitutional guarantees and public policy. ${ }^{136}$ From that springboard, the class comes to appreciate that while precedent may bind us, it does not force us to blindly accept its flaws. She teaches that advocates must have the discernment and the courage to know when to stand up for clients by challenging wrongful precedent. ${ }^{137}$ The class then takes up the seminal case where such a challenge to the hearsay exception was waged successfully. ${ }^{138}$ There, the litigators' tenacity and skillfulness yielded a vindication of the Confrontation Clause's assurances. ${ }^{139}$

At bottom, the ability to derive meaning from our experiences as lawyers depends in significant measure on whether or not we are willing to believe that our profession is good and noble. I believe that it is, and I communicate that faith unabashedly. I ask my students to consider acting and speaking as if they love the law, and then to watch as their experiences begin to match their level of rhetoric.

Teaching with meaning can transmute "the dull details into romance." ${ }^{40}$ To that end, every February, right around Valentine's Day, my first year class celebrates Loving the Law. The event takes its name from remarks that Justice Cardozo made to the first graduating class of New York University Law School, where he urged the new lawyers to "love the law, and treat it as if you love it." In anticipation of the day, the group puts together a book of images, quotes, case law

133 See David Callies \& Paula Franzese, Residential Privilege: The Advent of the Guarded Subdivision, in America's Second Gilded Age? PersPectives in LaW AND Class DifFERENCES (Trina Jones \& Paul Carrington, eds., 2006); Sandel, supra note 132, at 202 ("The more things money can buy, the fewer the occasions when people from different walks of life encounter one another.").

${ }_{134}$ Sandel, supra note 130, at 202-03.

135 Prof. Jenny Carroll, supra note 112.

136 Prof. Jenny Carroll, supra note 112.

137 Prof. Jenny Carroll, supra note 112.

138 Prof. Jenny Carroll, supra note 112

139 Prof. Jenny Carroll, supra note 112

140 Oliver Wendell Holmes, SPEeches 96 (1913). 
excerpts and literary references that hold particular meaning for them, as well as a video montage of inspiring law-related clips from celebrated speeches, oral arguments, films and documentaries that represent the best that lawyers can be. Each student is invited to bring in a guest(s) who has made a difference in that student's life (whether a parent, spouse, partner, dear friend, or mentor) to join us for the celebration, during which we hear from practitioners, judges, policy-makers, upperclass students and faculty on why they have chosen to love the law and how they treat it as if they love it. ${ }^{141}$ The most satisfying part of the experience comes when each class member introduces his or her guest, indicating why that person matters so much. As lawyers, that is part of what I ask my students to do: to remember to see what needs to be seen and to remain anchored in gratitude for the people on whose shoulders they stand.

History teaches that the principal cause of human suffering is forgetfulness. I want my students to remember where they come from and to call to mind the struggles and sacrifices made by those who came before them, in generations past and in more recent memory. They have been called to this craft to vindicate the hopes and dreams of those ancestors. They are here to use the formidable instrument of the law to be givers of hope and a voice for those who have yet to find their own. As lawyers, they will close the gap between what is and what ought to be.

\section{CONCLUSION}

In these difficult times, as law teachers we are uniquely situated to frame the task of reinvention for both the academy and the profession. Staying relevant against the backdrop of significant demographic, socio-cultural and economic shifts that have altered the ways that the law is perceived, accessed and practiced requires that we re-think and re-brand the theoretical and practical skill sets that we teach. We better prepare our students for success in a conceptual age when we endeavor

141 It bears mentioning that when I first propose the idea for the day to the class, invariably and quite understandably some students are dubious, or simply not feeling the love. I acknowledge that response, but encourage the doubters to "fake it until you make it." So much of what we know about body language and linguistic-cultural connections reveals that we can act our way into a feeling by the words we choose and the postures we embrace. Noam Shpancer, Action Creates Emotion, PsYchol. TODAY (Oct. 25, 2010), http://www.psychologytoday.com/blog/insight-therapy/201010/ action-creates-emotion. One of the most gratifying aspects of the Loving the Law Day experience comes when a student, who was sure that the idea was goofy, later stops in to say that he was deeply moved and pleasantly surprised by the magnitude of the day and its effect on him. 
in all courses to access and fortify their whole mind aptitudes. We do that when we consciously cultivate a classroom environment where students, having studied and analyzed the weight of authority, critically assessing the logic applied (metaphorically left-mind aptitudes), can develop a cohesive experience about its meaning and applications (rightmind processes) and a baseline of proficiency that integrates both contextually deductive and emotional intelligences (whole mind). Meaning is enhanced when students are helped to forge a narrative about the given subject matter, linking that story to the larger historical, cultural and socio-economic frameworks of which given cases, statutory and regulatory authority are just a part. Most essentially, in the classroom adeptness is heightened when we present our students with opportunities to weave together the theoretical, doctrinal, historical and more contemporary contextual threads by applying those strands to settings that feel real.

The effort that the task of reinvention requires has effects that will transcend the exigencies of our time. Henry Adams put it aptly when he observed that "a teacher affects eternity; he can never know where his influence stops." ${ }^{142}$ Each of us will hold an enduring place in our students' intellectual, ethical and professional trajectories. As teachers, we are constantly modeling behaviors that will help to shape the caliber and appeal of those paths. Particularly now, with its very relevance at stake, it behooves us to remain acutely mindful of the power and opportunity that the craft, and our place in it, presents. We can teach and also show our students a view of the legal profession that is noble, honorable and, if justice is to be achieved, indispensable. The care that we take with each and every class can demonstrate our love for the law, our profession, and the sacred trust that we share with our students. At its best, our teaching is that love made visible.

142 Henry Adams, Failure, in The EducATION of Henry AdAMs (1871) (Project Gutenberg EBook), available at http://www.gutenberg.org/files/2044/2044-h/2044h.htm. 